\title{
Morphological correlates of sex differences in acoustic startle response and prepulse inhibition through projections from locus coeruleus to cochlear root neurons
}

\author{
Sebastian Hormigo ${ }^{1}\left(\mathbb{D} \cdot\right.$ Ricardo Gómez-Nieto ${ }^{1,2,3}$ - Consuelo Sancho ${ }^{1,2,4}$. \\ Javier Herrero-Turrión ${ }^{1,2} \cdot$ Juan Carro $^{1}$ - Dolores E. López ${ }^{1,2,3}$. \\ José de Anchieta de Castro e Horta-Júnior ${ }^{5}$
}

Received: 11 December 2016 / Accepted: 27 March 2017 / Published online: 5 April 2017

(C) Springer-Verlag Berlin Heidelberg 2017

\begin{abstract}
The noradrenergic locus coeruleus (LC) plays an important role in the promotion and maintenance of arousal and alertness. Our group recently described coerulean projections to cochlear root neurons (CRNs), the first relay of the primary acoustic startle reflex (ASR) circuit. However, the role of the LC in the ASR and its modulation, prepulse inhibition (PPI), is not clear. In this study, we damaged LC neurons and fibers using a highly selective neurotoxin, DSP-4, and then assessed ASR and PPI in male and female rats. Our results showed that ASR amplitude was higher in males at 14 days after DSP-4 injection when compared to pre-administration values and those in the male control group. Such modifications in ASR amplitude did not occur in DSP-4-injected females, which exhibited ASR amplitude within the range of control values. PPI differences between males and females seen in controls were not observed in DSP-4-injected rats for any interstimulus interval tested. DSP-4 injection did not affect ASR and PPI
\end{abstract}

Sebastian Hormigo

sebifisio@gmail.com

$\square$ José de Anchieta de Castro e Horta-Júnior anchieta@ibb.unesp.br

1 Institute for Neuroscience of Castilla y León (INCYL), University of Salamanca, Salamanca, Spain

2 Institute of Biomedical Research of Salamanca (IBSAL), University of Salamanca, Salamanca, Spain

3 Department of Cell Biology and Pathology, University of Salamanca, Salamanca, Spain

4 Department of Physiology and Pharmacology, University of Salamanca, Salamanca, Spain

5 Department of Anatomy, Institute of Biosciences of Botucatu, Univ. Estadual Paulista (UNESP), Distrito de Rubião Jr., S/N, PO.Box 510, Botucatu, SP 18618-689, Brazil latencies in either the male or the female groups, showing values that were consistent with the sex-related variability observed in control rats. Furthermore, we studied the noradrenergic receptor system in the cochlear nerve root using gene expression analysis. When compared to controls, DSP-4-injected males showed higher levels of expression in all adrenoceptor subtypes; however, DSP-4-injected females showed varied effects depending on the receptor type, with either up-, downregulations, or maintenance of expression levels. Lastly, we determined noradrenaline levels in CRNs and other LC-targeted areas using HPLC assays, and these results correlated with behavioral and adrenoceptor expression changes post DSP-4 injection. Our study supports the participation of LC in ASR and PPI, and contributes toward a better understanding of sex-related differences observed in somatosensory gating paradigms.

Keywords Adrenergic receptors - ASR pathway . Catecholamines · Dopamine beta-hydroxylase · DSP-4 . Noradrenaline $\cdot$ Somatosensory gating

\begin{tabular}{ll}
\multicolumn{2}{l}{ Abbreviations } \\
ABC & Avidin-biotin-peroxidase complex \\
ADRs & Adrenergic receptors \\
ASR & Acoustic startle reflex \\
BS & Brainstem \\
Cb & Cerebellum \\
CRNs & Cochlear root neurons \\
DAB & $3,3^{\prime}$ Diaminobenzidine tetrahydrochloride \\
DBH & Dopamine beta-hydroxylase \\
DHBA & 3,4-Dihydroxybenzylamine \\
DSP-4 & $N$-(2-chloroethyl)- $N$-ethyl-2-bromoben- \\
& zylamine \\
HPAA & 4-Hydroxyphenylacetic acid \\
HPLC & High-performance liquid chromatography
\end{tabular}

Abbreviations

ABC Avidin-biotin-peroxidase complex

ADRs Adrenergic receptors

ASR Acoustic startle reflex

Brainstem

$\mathrm{Cb} \quad$ Cerebellum

CRNs Cochlear root neurons

DAB 3,3' Diaminobenzidine tetrahydrochloride

DBH Dopamine beta-hydroxylase

DHBA 3,4-Dihydroxybenzylamine

DSP-4 $N$-(2-chloroethyl)- $N$-ethyl-2-bromoben-

HPLC High-performance liquid chromatography 


$\begin{array}{ll}\text { IC } & \text { Inferior colliculus } \\ \text { IHC } & \text { Immunohistochemistry } \\ \text { ISI } & \text { Interstimulus interval } \\ \text { LC } & \text { Locus coeruleus } \\ \text { MHPG } & \text { 3-Methoxy-4-hydroxyphenylglycol } \\ \text { NA } & \text { Noradrenaline } \\ \text { PFC } & \text { Prefrontal cortex } \\ \text { PB } & \text { Phosphate buffer } 0.1 \mathrm{M}, \text { pH 7.4 } \\ \text { PBS } & \text { Phosphate buffered saline } \\ \text { PPI } & \text { Prepulse inhibition } \\ \text { RT-qPCR } & \begin{array}{l}\text { Reverse transcription-quantitative polymerase } \\ \text { chain reaction }\end{array}\end{array}$

\section{Introduction}

The acoustic startle reflex (ASR) is a short and intense motor reaction that involves contraction of large numbers of muscle groups throughout the body in response to a loud and unexpected acoustic stimulus (Yeomans and Frankland 1995). The ASR is a non-selective attentional phenomenon (Bakker et al. 2006), and has also a vegetative component mediated by the autonomic nervous system, increasing blood pressure and heart rate (Landis and Hunt 1939; Baudrie et al. 1997). The ASR serves as a defensive reflex triggered by the brainstem against possible aggression or alert against unexpected events (Keay et al. 1988). In fact, the primary ASR pathway involves just three synapses in the rat central nervous system, onto the cochlear root neurons (CRNs), the pontine reticular formation (caudal portion), and the spinal motoneurons (Lee et al. 1996; Gómez-Nieto et al. 2014b). The ASR can be modulated quantitatively or qualitatively through sensory gating processes by a series of natural or experimental conditions (Swerdlow et al. 2000; Bell et al. 2003). The modulations of ASR are more sensitive than the reflex itself and present significant alterations in situations where the reflex itself is not altered (Hoffman and Ison 1980; Justus and Finn 2007). One of the more studied modulations of ASR is the prepulse inhibition (PPI), a neurological phenomenon in which a weaker pre-stimulus (prepulse) inhibits the reaction to a subsequent strong startling stimulus (pulse) (Hoffman and Ison 1980; Valls-Solé 1998, 2012). The PPI is an adaptive mechanism to prevent over-stimulation, helping the brain focus on a specific stimulus among a host of other distracters (Braff et al. 1978). Consequently, PPI provides operational measures of information processing by filtering irrelevant stimuli (Swerdlow et al. 2001). Since ASR and PPI can be easily tested in humans and rats, these behavioral paradigms are used as valuable tools for translational research on disorders with attentional and informationprocessing dysfunctions (Swerdlow and Geyer 1998; Braff and Geyer 1990; Swerdlow et al. 2001; Fendt et al. 2001;
Li et al. 2009; Molina et al. 2009). The modulations of the ASR are related to structures of the central nervous system that act on some of the descending systems and end up to influence the activity of the nuclei of the primary ASR pathway. Up to date, it is unknown that the neuronal correlate of the CRNs in humans and shedding light on the projections to CRNs is crucial to make rodents relevant as experimental models of impaired sensorimotor gating, in which PPI is used as a biomarker for healthy brain circuitry.

Responses of the CRNs are strongly inhibited by acoustic prepulses (Gómez-Nieto et al. 2010, 2014b), and hence it has been suggested that CRNs are modulated in auditory PPI. Thus, it is essential to investigate the source of inputs to the CRNs for understanding the neural mechanisms underlying modulation of the ASR response by auditory prepulses (Gómez-Nieto et al. 2008a, b, 2014a). Recently, our group described a projection to the CRNs from the locus coeruleus (LC) (Gómez-Nieto et al. 2008b; Hormigo et al. 2015). The LC is a structure located in the caudal central gray of the pons in the floor of the fourth ventricle. It is involved in many sympathetic effects during stress by increasing noradrenaline (NA) production. Electrophysiological studies demonstrated that the LC is activated by various stressful stimuli (Valentino et al. 1983; Page et al. 1992; Valentino and Van Bockstaele 2008), noxious or nociceptive stimuli (Singewald et al. 1995; Couto et al. 2006; Tsuruoka et al. 2011), and physiological stimuli such as hypotension, hypoxia, and visceral stimulation (MiaoKun 1995; Ma et al. 2008). The LC is the main source of NA for both the brainstem and the forebrain (Aston-Jones and George 2004), and its metabolic pathways can be finely regulated when there is an increase in the demand for NA synthesis, e.g., in a stressful situation (Rosario and Abercrombie 1999; Asakura et al. 2000) or in the detection of novel stimuli (Foote et al. 1980; Grant et al. 1988). The LC is also involved in the regulation of the circadian rhythm (Aston-Jones and Bloom 1981), maintaining alertness to relevant environmental stimuli (Aston-Jones et al. 1991), learning (Sara and Segal 1991; Sullivan et al. 1994), and attentional processes (Aston-Jones et al. 1999). Given that the CRNs are under noradrenergic influence from the LC (Hormigo et al. 2015), the ASR is liable to be modulated by LC activity.

The goal of this study is to determine the role that the LC might play in ASR modulation by auditory prepulses. We used a highly selective neurotoxin to impair the LC neurons and fibers in male and female rats, and then measured ASR and PPI comparing the results with those from the same animals prior to LC impairment, and with those from saline-injected controls. Interestingly, ASR and PPI are found to show sex-related differences in both humans and rats (Lehmann et al. 1999; Braff et al. 2001; Aasen et al. 2005). The LC is a sexually dimorphic structure (Pinos 
et al. 2001; Bangasser et al. 2011; Hormigo et al. 2015), and we have previously found that CRNs exhibit important sex-specific differences in gene expression of adrenoreceptors (Hormigo et al. 2015). Therefore, we attempt to determine whether the LC-CRN projection is part of the neuronal substrates that correlate the sex differences observed in the ASR and PPI paradigms.

\section{Materials and methods}

\section{Animals}

Adult albino male and female Wistar rats (Charles River, Barcelona, Spain) aged 12-16 weeks and weighing 230-310 g were cared for and used in these experiments. All applicable international, national, and/or institutional guidelines for the care and use of animals were followed. Experimental procedures were conducted according to the guidelines of the Spanish (RD 53/2013, BOE 34/11370421, 2013), European (2010/63/EU), and São Paulo State University-UNESP directives, under the supervision of the corresponding Institutional Animal Care and Use Committees. Animals were housed in groups of two or three and all efforts were made to avoid unnecessary suffering.

\section{Neurotoxic lesion with DSP-4}

Diverse studies have shown that the neurotoxin $\mathrm{N}$-(2chloroethyl)- $N$-ethyl-2-bromobenzylamine (DSP-4) can be used for investigating the functional roles of NA in the brain (Fritschy and Grzanna 1989; Grzanna et al. 1989; Fritschy et al. 1991; Ross et al. 1973). In rodents, a systemic injection of DSP-4 causes depletion of the levels of NA, the release capacity, and the activity of dopamine betahydroxylase (DBH) from the LC (Ross et al. 1973; Ross 1985).

The animals were divided in two groups: DSP-4-injected, (37 male and 42 female rats) in which a single intraperitoneal dose of $50 \mathrm{mg} / \mathrm{kg}$ of DSP-4 (Sigma-Aldrich Co, St. 234 Louis, MO, United States) was administrated; and control, (38 male and 43 female rats) in which saline was injected intraperitoneally.

\section{ASR parameters assessment}

Each animal, either control or DSP-4-injected, was tested for the ASR and PPI at 3 different time points: the day prior to the injection (either saline or DSP-4), and at 7 and 14 days after the injection. Using a SR-LAB system (SDI, San Diego, CA, USA), we assessed ASR and PPI in a session routinely performed in our laboratory (Castellano et al. 2009; Gómez-Nieto et al. 2014a). Rats were exposed to a background white noise ( $65 \mathrm{~dB}$ SPL) that continued throughout the experimental session. A session consisted of an acclimatizing period of $\sim 5$ min followed by 80 trials presented pseudo-randomly, with a mean inter-trial interval of $30 \mathrm{~s}$. Sixteen of the trials involved a single-noise startle stimulus pulse (115 dB SPL, 20 ms of burst of white noise); the remaining trials consisted of 4 blocks of 16 trials of a white noise prepulse ( $80 \mathrm{~dB}$ SPL, $20 \mathrm{~ms}$ of burst of white noise), followed by the startle stimulus pulse (as above), each block consisting of a different interstimulus interval (ISI): either $25,50,100$, or $150 \mathrm{~ms}$. Whole-ballistic movements of the rats corresponding to startling responses were recorded with a piezoelectric accelerometer, converted from analogical to digital signals and analyzed by the SRLAB system that provided two main values of interest: $V_{\max }$ and $T_{\max } . V_{\max }$ represents the peak startle response (ASR amplitude in arbitrary units,) that occurs during each trial, while $T_{\max }$ is the time from stimulus onset to the peak startle response (ASR latency in $\mathrm{ms}$ ). The percentage of inhibition (\%PPI) of the animal's response to the startle stimulus was calculated for each respective ISI according to the following formula: \%PPI = [startle amplitude on pulse-alone trial-startle amplitude on prepulse to pulse trial (either 25, 50,100 , or $150 \mathrm{~ms}$ of ISI)/startle amplitude on pulse-alone trial $] \times 100$. We also calculated the inter-session ratio startle amplitude as a percentage by comparing the mean of the ASR amplitude at day 7 and day 14 post injection vs. day 0 according to the following formula: [mean startle amplitude on pulse-alone trial (day 0)-mean startle amplitude on pulse-alone trial (either day 7 or 14)/mean startle amplitude on pulse-alone trial (day 0 ) $] \times 100$.

\section{Tissue preparation for histology}

Rats were euthanized with a sodium pentobarbital overdose and then perfused transcardially with $100 \mathrm{ml}$ of fresh Ringer calcium-free buffer $(\mathrm{NaCl}, 145.45 \mathrm{mM} ; \mathrm{KCl}$, $3.35 \mathrm{mM}$; $\mathrm{NaHCO}_{3}, 2.38 \mathrm{mM}$ ), $\mathrm{pH} 6.9$, at $37^{\circ} \mathrm{C}$, followed by $1000 \mathrm{ml}$ of fresh depolymerized $4 \%$ paraformaldehyde in $0.1 \mathrm{M}$ phosphate buffer, $\mathrm{pH} 7.4(\mathrm{~PB})$, at room temperature. Brains were then removed and cryoprotected for $48 \mathrm{~h}$ at $4{ }^{\circ} \mathrm{C}$ in $30 \%$ sucrose in PB $0.1 \mathrm{M}$. Serial coronal sections (40 $\mu \mathrm{m}$ in thickness) were cut on a freezing stage sliding microtome (HM430; Microm, Heidelberg, Germany).

\section{Immunohistochemical procedure for DBH and CaBP}

We used 12 animals, 6 males ( 3 control and 3 DSP4 -injected) and 6 females ( 3 control and 3 DSP-4-injected), to study the pattern of DBH immunoreactivity in the LC and the cochlear nerve root. After perfusion and serial section protocol, we followed identical immunohistochemistry (IHC) procedures to those used in 
our previous studies (Hormigo et al. 2012, 2015). The antibodies used and their dilution are shown in Table 1. Free-floating sections were incubated with primary antibody anti-DBH for $72 \mathrm{~h}$ at $4{ }^{\circ} \mathrm{C}$, washed and incubated with its corresponding biotinylated secondary antibody for $2 \mathrm{~h}$ at room temperature. Following removal of the secondary antibodies, sections were incubated with an avidin-biotin-peroxidase complex (ABC, Standard-kit \#PK 4000; Vector Laboratories, Burlingame, CA, USA) for $2 \mathrm{~h}$ and visualized with a 3,3'diaminobenzidine tetrahydrochloride (DAB) with heavy-metal intensification. After that, sections followed the calbindin proteinD28 $\mathrm{K}(\mathrm{CaBP}) \mathrm{IHC}$ procedure, in which the $\mathrm{CaBP}$ was visualized without a nickel-intensified peroxidase reaction. This allowed to distinguish CRNs immunolabeled for $\mathrm{CaBP}$ (as a brown reaction product) from the black staining of the DBH-immunolabeled fibers and terminals (Hormigo et al. 2015). All sections were mounted on slides, dehydrated, and coverslipped with Entellan ${ }^{\circledR}$ Neu (Merck, Darmstadt, Germany). In addition, several series were counterstained with cresyl violet $0.1 \%$ (\#5235, Merck) for cytoarchitectonic reference, chiefly to identify the different parts of the LC and the surrounding anatomical structures, following the nomenclature described elsewhere (Paxinos and Watson 2005).

\section{Image analysis}

Histological sections were studied using a microscope (\#BX5; Olympus, Center Valley, PA, USA) equipped with a digital camera (Spot Rt@; Diagnostic Instruments, Sterling Heights, MI, USA). Low-magnification images were taken with a $5 \times$ objective lens, and high-magnification images were taken with $20 \times$ and $40 \times$ objective lenses. To obtain the number of DBH-immunostained neurons of the LC, we selected sections processed without nickel-intensified peroxidase reaction, in which individual positive neurons were clearly distinguishable to perform manual counts in photomicrographs taken with a 40x objective. All photomicrographs shown in the figures were processed with minor modifications in brightness and contrast using Adobe Photoshop ${ }^{\circledR}$ (version 9.0; Adobe Systems Incorporated, San Jose, CA, USA). Canvas ${ }^{\circledR}$ (version X Build 885, ACD Systems Inc, USA) was used for the assemblage of the figures.

\section{Gene expression analysis: RT-qPCR}

After the last ASR assessment session (at day 14 post injection) cochlear nerve roots were collected after craniotomy and removal of the brain. The roots of the cochlear nerve were sectioned with an ophthalmic forceps using as reference the ventral surface of the ventral cochlear nucleus. The cochlear nerve roots were collected

Table 1 List of antibodies and dilutions used for the immunohistochemical approaches

\begin{tabular}{|c|c|c|c|c|c|c|}
\hline Antigen & Primary antibody & Reference & Dilution & Secondary antibody & Reference & Dilution \\
\hline Dopamine $\beta$-hydroxylase & Rabbit anti-DBH pAb & DZ1020-Aff & $1 / 500$ & $\begin{array}{l}\text { Biotinylated goat anti- } \\
\text { rabbit }\end{array}$ & \#BA-1000-Vector & $1 / 200$ \\
\hline$\alpha-1$ Adrenergic receptor & Rabbit anti-ADR $\alpha 1 \mathrm{pAb}$ & PA1-047- Aff & $1 / 150$ & $\begin{array}{l}\text { Biotinylated goat anti- } \\
\text { rabbit }\end{array}$ & \#BA-1000-Vector & $1 / 200$ \\
\hline$\alpha-2 \mathrm{~A}$ adrenergic receptor & $\begin{array}{l}\text { Rabbit anti-ADR } \alpha 2 \mathrm{~A} \\
\mathrm{pAb}\end{array}$ & PA1-048- Aff & $1 / 150$ & $\begin{array}{l}\text { Biotinylated goat anti- } \\
\text { rabbit }\end{array}$ & \#BA-1000-Vector & $1 / 200$ \\
\hline$\beta-2$ adrenergic receptor & Rabbit anti-ADR $\beta 2 \mathrm{pAb}$ & 905-742-100- AD-P & $1 / 150$ & $\begin{array}{l}\text { Biotinylated goat anti- } \\
\text { rabbit }\end{array}$ & \#BA-1000-Vector & $1 / 200$ \\
\hline $\mathrm{CaBP}$ & Mouse anti-CaBP & \#C-8666/ Sigma & $1 / 200$ & $\begin{array}{l}\text { Biotinylated horse anti- } \\
\text { mouse }\end{array}$ & \#BA-200-Vector & $1 / 200$ \\
\hline
\end{tabular}

Specificity of the DZ1020 antibody: the dopamine $\beta$-hydroxylase precursor recombinant protein epitope signature tag (PrEST). Immunogen sequence: VQRTPEGLTLLFKRPFGTCDPKDYLIEDGTVHLVYGILEEPFRSLEAINGSGLQMGLQRVQLLKPNIPEPELPSDACTMEVQAPNIQIPSQETTYWCYIKELPKGFSRHHIIKYEPIVTKGN

Specificity of the PA1-047 antibody: the $\alpha$-1 Adrenergic Receptor immunogen is a synthetic peptide corresponding to residues K(339)FSREKKAAKT(349) of the 3rd intracellular loop of human ADR $\alpha 1$. This sequence is 100\% conserved in all ADR $\alpha 1$ subtypes examined, including rat Specificity of the PA1-048 antibody: the $\alpha-2 \mathrm{~A}$ Adrenergic Receptor immunogen is a synthetic peptide corresponding to residues R(218) IYQIAKRRTRVPPSRRG(235) of the 3rd intracellular loop of human ADR $\alpha 2$ A. This sequence is completely conserved between human, mouse, rat, and porcine ADR $\alpha 2 \mathrm{~A}$

Specificity of the 905-742-100 antibody: the $\beta-2$ adrenergic receptor immunogen is a synthetic peptide derived from sequence on the aminoterminus of mouse $\beta 2$ adrenergic receptor. This sequence is completely conserved between human, mouse, and rat ADR $\beta 2$

AD-P assay designs proteimax, 5777 Himes Drive, Ann Arbor, MI 48108, USA; Aff Affinity bioreagents, 4620 Technology Drive, Suite 600. Golden, CO 80403 USA; pAB polyclonal antibody; Vector Vector Laboratories, Burlingame, CA, USA 
bilaterally and homogenized (Brinkmann Polytron) to study gene expression levels of adrenoceptors in 39 males (19 control and 20 DSP-4-injected) and 49 females (24 control and 25 DSP-4-injected). Total RNA was extracted using TRIZOL $®$ (Gibco BRL, Gaithersburg, MD, USA) following the manufacturer's protocol. Every sample was then purified by removing possible genomic DNA contamination using a commercial kit (RNeasy Mini Kit, Qiagen, Hilden, Germany) and following the manufacturer's protocol. RNA quantification was carried out using a NanoPhotometer (Implen $\mathrm{GmbH}$ ); and RNA quality assessed on an RNA 6000 NanoLabChip (Agilent Technologies, Palo Alto, CA, USA) using an Agilent 2100 Bioanalyzer to test the integrity of the $18 \mathrm{~S}$ and $28 \mathrm{~S}$ rRNA bands, and the RNA integrity number (RIN). Only RNA samples with a RIN of at least 7.5 (0-10 range) were used, with the vast majority of samples being 8.0 or higher.

Total RNA $(2 \mu \mathrm{g})$, primed with oligo-dT, was reversetranscribed into cDNA at $37{ }^{\circ} \mathrm{C}$ for $2 \mathrm{~h}$ using an ImProm-II Reverse Transcription System (Promega Corporation, Madison, WI, USA) in a $20 \mu \mathrm{l}$ volume, and stored at $-20{ }^{\circ} \mathrm{C}$ until use, according to manufacturer's instructions. In all cases, a reverse transcriptase negative control was used for testing genomic DNA contamination. Plus, DNAse injection (Turbo DNA-free Kit, Applied Biosystems) was also performed at $37{ }^{\circ} \mathrm{C}$ for $2 \mathrm{~h}$ in order to remove DNA contamination, followed by inactivation of the DNAses at $75^{\circ} \mathrm{C}$ for $15 \mathrm{~min}$.

The qPCR was performed with $1 \mathrm{ng}$ of cDNA from each sample using the SYBR-Green method. The SYBRGreen was included in a $2 \times$ Master Mix [SYBR-Green dye, dNTPs, passive reference (ROX), AmpliTaq1 Gold DNA polymerase] from Applied Biosystems (Madrid, Spain). Final volume of each reaction was $20 \mu \mathrm{l}: 10 \mu \mathrm{l}$ of Master Mix, $0.8 \mu \mathrm{l}$ of each oligonucleotide (Table 2), $7.4 \mu \mathrm{l}$ of MilliQ water, and $1 \mu \mathrm{l}$ of cDNA in a concentration of $1 \mathrm{ng} / \mu \mathrm{l}$. A standard curve was constructed for each experiment by serial dilutions of cDNA: 10, 1, 0.1, and $0.01 \mathrm{ng} /$ $\mu \mathrm{l}$. The amplification reaction took place in an ABI Prism 7000 detection system (Applied Biosystems), with the following conditions: $10 \mathrm{~min}$ at $95^{\circ} \mathrm{C}$ followed by 40 cycles of $15 \mathrm{~s}$ at $95{ }^{\circ} \mathrm{C}$ and $1 \mathrm{~min}$ at $60{ }^{\circ} \mathrm{C}$, and the results were analyzed using Dissociation Curve program (Applied Biosystems). Melting point curves were included to confirm that only one product was formed. Number of cDNA molecules was calculated by comparison with a standard curve of known amounts of the corresponding PCR products. Three PCR reactions were performed for each sample per plate, and each experiment was repeated three times. The housekeeping rat $\beta$-actin gene (Table 2) was used as reference gene (also known as endogenous control) and RNAfree (negative) control sample. All primers had at least one primer crossing an exon-exon boundary. The primers were

Table 2 PCR primers used in the genetic expression analysis

\begin{tabular}{|c|c|c|c|c|c|c|}
\hline Target protein & Number GenBank* & Primer forward & cDNA forward* & Primer reverse & cDNA reverse* & $\begin{array}{l}\text { Size of } \\
\text { prod- } \\
\text { ucts }\end{array}$ \\
\hline$\beta$-Actin & NM_031144 & $\begin{array}{l}\text { AGCCATGTACGTAGCCAT } \\
\text { CC }\end{array}$ & $471-490$ & $\begin{array}{l}\text { ACCCTCATAGATGGG } \\
\text { CACAG }\end{array}$ & $566-585$ & 115 \\
\hline $\mathrm{ADR} \alpha 1 \mathrm{~A}$ & NM_017191 & $\begin{array}{l}\text { ATCTCCATCGGACCCCTG } \\
\text { TT }\end{array}$ & $484-503$ & $\begin{array}{l}\text { GGCCAGTGGCACGTA } \\
\text { GAAAG }\end{array}$ & $590-609$ & 126 \\
\hline $\mathrm{ADR} \alpha 1 \mathrm{~B}$ & NM_016991 & $\begin{array}{l}\text { AGAATCTGGAGGCGG } \\
\text { GAGTC }\end{array}$ & $1093-1112$ & $\begin{array}{l}\text { CCTTGGCCTTGGTACTGC } \\
\text { TG }\end{array}$ & $1184-1203$ & 111 \\
\hline $\mathrm{ADR} \alpha 1 \mathrm{C}$ & NM_024483 & $\begin{array}{l}\text { TGCCTCTGGGCTCTCTGT } \\
\text { TC }\end{array}$ & $1564-1583$ & $\begin{array}{l}\text { TGAGCGGGTTCACAC } \\
\text { AGCTA }\end{array}$ & $1653-1662$ & 99 \\
\hline $\mathrm{ADR} \alpha 2 \mathrm{~A}$ & NM_012739 & $\begin{array}{l}\text { GATGCGCTGGACCTA } \\
\text { GAGGA }\end{array}$ & $865-884$ & $\begin{array}{l}\text { AGACTGTCCCCCGGT } \\
\text { TTCAC }\end{array}$ & $976-995$ & 131 \\
\hline $\mathrm{ADR} \alpha 2 \mathrm{~B}$ & NM_138505 & $\begin{array}{l}\text { TTTGCTCCCTGCCTCATC } \\
\text { AT }\end{array}$ & $924-943$ & $\begin{array}{l}\text { GGGGCTTCTTGGACT } \\
\text { CACCT }\end{array}$ & $1025-1044$ & 121 \\
\hline $\mathrm{ADR} \alpha 2 \mathrm{C}$ & NM_007418 & $\begin{array}{l}\text { GCTGCCAGAACCGCT } \\
\text { CTTTA }\end{array}$ & $2547-2566$ & $\begin{array}{l}\text { TGAAAGAGCGCCTGA } \\
\text { AGTCC }\end{array}$ & $2634-2653$ & 107 \\
\hline $\mathrm{ADR} \beta 1$ & NM_012701 & $\begin{array}{l}\text { CTTTCTACGTGCCCCTGG } \\
\text { TG }\end{array}$ & $819-838$ & $\begin{array}{l}\text { GCTGAGGTTTTGGGC } \\
\text { ATGAA }\end{array}$ & $918-937$ & 119 \\
\hline $\mathrm{ADR} \beta 2$ & NM_012492 & $\begin{array}{l}\text { TTCATGCCCAAAACC } \\
\text { TCAGC }\end{array}$ & 918-937 & $\begin{array}{l}\text { TGCCCATGATGATGCCTA } \\
\text { AA }\end{array}$ & $1021-1040$ & 123 \\
\hline $\mathrm{ADR} \beta 3$ & NM_013108 & $\begin{array}{l}\text { CTCCATCCCCTGCCA } \\
\text { CAGT }\end{array}$ & 980-999 & $\begin{array}{l}\text { GCCCATAATGAGACC } \\
\text { CAAGG }\end{array}$ & $1087-1109$ & 128 \\
\hline
\end{tabular}

Primer location in the corresponding GenBank sequences of rat origin is indicated 
designed to have similar melting temperatures and to give similar amplicon sizes (Table 2).

The threshold cycle $(\mathrm{Ct})$ values were obtained for each gene. Following the removal of outliers according to Burns et al. (2005), raw fluorescence data were used to determine the PCR amplification efficiency. All amplifications had a PCR efficiency value of 1.90-2.10; PCR efficiency values close to 2.0 have been taken to suggest efficient amplification. The PCR efficiency of each primer pair, together with $\mathrm{Ct}$ values, was used to calculate a relative gene expression value for each transcript, according to the equation $E^{-(\Delta \mathrm{Ct}}$ "condition 1"- $\Delta \mathrm{Ct}$ "condition 2"), where $E$ refers to PCR efficiency, $\Delta \mathrm{Ct}$ of each "condition" ("condition 1" is the treated sample and "condition 2", the untreated control) is equal to $\mathrm{Ct}$ "gene of interest"-Ct "internal control" (Livak and Schmittgen 2001; Schmittgen and Livak 2008). A standard error for each relative gene expression value was calculated as a measure of data variation.

\section{Biochemical monoamine quantification: HPLC}

We collected 5 different brain regions after the last ASR assessment session (at day 14 post injection): cochlear nerve root (as previously described), brainstem (from the coronal plane at the level of caudal end of cerebellum to the coronal plane just cranial to superior colliculus), cerebellum (separated from the brainstem after dissection of cerebellar peduncles), inferior colliculus (dissected from the brainstem with an ophthalmic forceps), and prefrontal cortex (after dissection of cerebral cortex just cranial to a coronal plane at the level of optic chiasm), as known LC-innervated projection targets to study the impact of the LC-NA system impairment throughout the brain in 25 males (14 control and 11 DSP-4-injected) and 23 females (12 control and 11 DSP-4-injected). Two different biochemical compounds were quantified using mass spectrometry: the amine NA; and the carboxylic acid MHPG (3-methoxy4-hydroxyphenylglycol), a NA metabolite. As internal standards, we used 3,4-dihydroxybenzylamine (DHBA) for the amine, and 4-hydroxyphenylacetic acid (HPAA) for the carboxylic acid.

Each brain region was sonicated in $1 \mathrm{ml}$ of $0.1 \mathrm{M}$ perchloric acid. A $100 \mu \mathrm{l}$ aliquot of the sonicated material was stored at $-80{ }^{\circ} \mathrm{C}$ for protein determination using Bradford's technique (Bradford 1976). The supernatant was collected from centrifugation of the sonicated material at 13,000 $\mathrm{g}$ for $15 \mathrm{~min}$. The internal standard (in known concentration, $10 \mathrm{E}-4 \mathrm{M}$ ) was then added, plus $25 \mathrm{mg}$ of alumina, $50 \mu \mathrm{l}$ of $5 \mathrm{mM}$ sodium metabisulfite, and $400 \mu \mathrm{l}$ of $10 \mathrm{mM}$ Tris- $1 \mathrm{mM}$ EDTA $\mathrm{pH} 8$ adjusted with $\mathrm{HCl}$. The solution was mixed and shaken for $10 \mathrm{~min}$. After centrifugation at $11,000 \mathrm{~g}$ for $5 \mathrm{~min}$, the carboxylic acid eluted and was submitted to mass spectrometry. The amine remained in the supernatant, which was placed into a fresh tube. The alumina was washed twice with $1.5 \mathrm{ml}$ of MilliQ $\mathrm{H}_{2} \mathrm{O}$ and spun. Finally, we added $100 \mu \mathrm{l}$ of $0.1 \mathrm{M}$ perchloric acid plus $0.1 \mathrm{mM}$ sodium metabisulfite $(7: 3)$ to elute the amines. All reagents for the HPLC experiments were purchased from Sigma-Aldrich (St. Louis, MO, USA).

Liquid chromatography was developed from reversedphase methods. We injected $100 \mu \mathrm{l}$ of the reconstituted extract onto an Atlantis ${ }^{\circledR}$ T3 C18 reversed-phase stainlesssteel column $(100 \times 2.1 \mathrm{~mm}, 3 \mu \mathrm{m})$, using a Model 2795 HPLC automated sample processor (both from Waters Associates, Milford, MA). The HPLC program is summarized in Table 3a. Mobile phase was pumped at a flow rate of $1 \mathrm{ml} / \mathrm{min}$ by a Waters Model 2795 programmable solvent-delivery system. To quantify the catecholaminergic compounds as they were eluted from the column, we used a ZQ4000 quadrupole mass spectrometer (Waters Associates, Milford, MA, USA). For the quadrupole setup, we measured all compounds in known concentrations (between the range we expected to find our experimental samples, $10^{-6}$ to $10^{-10} \mathrm{M}$ ) prepared from stock solutions both in preextraction samples and in post-extraction samples, which served as quality controls. Finally, the quadrupole was set as shown in Table 3b. Positive signals were followed for detection of the amines, and negative signals were followed for the detection of the carboxylic acids, taking into account the analytical recovery of the internal standards (either DHBA or HPAA, respectively). Data of the DSP4-injected groups are expressed as a percentage of the difference from control specimens.

\section{Statistical analysis}

Data are reported as means \pm SEM. They were analyzed for normal distribution according to the Shapiro-Wilk normality test, and parametric statistics were used. Conditions were compared by either unpaired Student's $t$ test assuming unequal variances (DSP-4-treated vs. control), one-way analysis of the variance (DSP-4-treated vs. control attending to sex), and/or mixed model for repeated measurements (split plot to compare measurements at day 0 , day 7, and day 14). The variable "inter-" was the different groups (males and females, either control or DSP-4-treated) and variable the "intra-" was the different days measured (day 0 , day 7 , and day 14 post injection). When appropriate, a Bonferroni test was used for post hoc comparisons. The statistical software SPSS/PASW (version 18.0.0, SPSS Inc., Chicago, IL, USA) was used to complete statistical analysis. Results were considered significant when $* p<0.05 ; * * p<0.01 ; * * * p<0.001$. Non-significant values were reported as n.s. 
Table 3 HPLC program

\begin{tabular}{|c|c|c|}
\hline Time (min) & $1(\%)$ & $2(\%)$ \\
\hline \multicolumn{3}{|l|}{ (a) } \\
\hline 0 & 95 & 5 \\
\hline 5 & 95 & 5 \\
\hline 15 & 75 & 25 \\
\hline 20 & 75 & 25 \\
\hline Compound & Ion used (Amu) & Cone voltage $(\mathrm{V})$ \\
\hline \multicolumn{3}{|l|}{ (b) } \\
\hline NA & 152 & 30 \\
\hline DHBA & 123 & 30 \\
\hline MHPG & 151 & 30 \\
\hline HPAA & 151 & 30 \\
\hline
\end{tabular}

In $\mathrm{A}$, time shows the percentage in which solutions were added in the mass spectrometry column. In B, settings of the quadrupole mass spectrometer to follow the different compounds

Amu atomic mass unit, $V$ volts

1: $20 \mathrm{mM}$ Ammonium formate $\mathrm{pH} 3$

2: Acetonitrile

\section{Results}

\section{Lack of DBH immunoreactivity in the LC following DSP-4 administration}

To analyze the effect of DSP-4 on the LC-NA system, we ran IHC assays to measure dopamine beta-hydroxylase $(\mathrm{DBH})$ immunoreactivity, the enzyme that transforms dopamine into NA. In control rats, we observed a dense staining along the $\mathrm{LC}$ region in both females (Fig. 1a) and males (Fig. 1b). We further observed two immunostained middle-sized neuron shapes: multipolar and fusiform. The LC was divided into ventral and dorsal parts based on cytoarchitecture. Multipolar immunostained neurons were predominantly located in the ventral part of the LC and they were less densely packed, whereas fusiform immunostained neurons (Fig. 1e) were mainly located in the dorsal part of the LC, and they were more densely packed. In DSP-4-injected rats, IHC assays showed a major decrement of staining in the $\mathrm{LC}$ region in both females (Fig. 1c) and males (Fig. 1d), leaving just a few labeled neurons scattered in the nucleus. Contrary to control rats, DBH immunoreactivity in the LC of DSP-4-injected rats was greatly reduced that we did not observe the neuroanatomical divisions of the LC (Fig. 1c, d). Control females presented slightly higher numbers of immunostained neurons in the LC compared to males (Fig. 1f). DSP-4-injected rats exhibited only around $10 \%$ of immunostained neurons compared to controls $(* * * p<0.001)$, in both males and females (Fig. 1f). The ratio of neurons between females and males (3.9-3.2) was maintained after neurotoxic treatment, suggesting DSP-4 promoted equivalent effects in both sexes (Fig. $1 \mathrm{f}$ ).

\section{Lack of DBH immunoreactivity in the cochlear root nucleus following DSP-4 administration}

We observed in control rats dense DBH-immunoreactive fibers and varicosities throughout the dorsoventral axis of the cochlear nerve root nucleus (Fig. 2a, b), and labeled fibers terminating in numerous endings onto the cell bodies and primary dendrites of CRNs (Fig. 2b, arrowheads). This described DBH-immunoreactive fibers and boutons were not present in the nerve root nucleus of DSP-4-injected rats (Fig. 2c, d). Double IHC experiments for DBH and CaBP revealed the absence of noradrenergic fibers or endings onto the cell bodies or dendrites of CRNs (Fig. 2d). Taking into account the above results, it can be inferred that the DSP-4 injection was effective and yielded a noradrenergic LC impairment in treated rats.

\section{Impairment of the LC-NA system promotes changes in ASR response and PPI parameters with differences between sexes}

Using males and females with impaired LC-NA systems, we studied the possible role of the LC in the startle reflex circuit through a longitudinal approach. A day prior to injection of either saline or DSP-4 (day 0), each animal was tested for ASR and PPI parameters. We did not find any significant $\left(F_{(1,92)}=0.25, p=0.61\right)$ difference in the intensity of the startle reflex between males and females, with males exhibiting higher ASR amplitude (Fig. 3a). At day 7 post injection, ASR amplitudes tended to decrease, although there was no significant difference when compared to day $0\left(F_{(1,91)}=0.48, p=0.56\right)$. This reduction was more pronounced in DSP-4 females than controls, whereas the opposite trend was observed in males (Fig. 3a). At day 14 post injection, ASR amplitude in DSP-4 males was significantly increased $\left(F_{(1,92)}=3.24, p<0.01\right)$ displaying the highest recorded values (Fig. 3a), whereas this phenomenon was not observed in DSP-4 females. This result suggests the LC might be executing different roles in the startle reflex circuit depending on the sex.

We also observed a decrement in the inter-session ratio of startle amplitude in the experimental groups ranging from 7 to $14 \%\left(F_{(1,89)}=4.41, p<0.05\right)$ at days 7 and 14 post injection compared to day 0 (Fig. 3b), except for DSP-4 males which exhibited an increment in the amplitude of the ASR of approximately $12 \%\left(F_{(1,89)}=2.88\right.$, $p<0.01$ ) (Fig. 3b). In other words, males with an impaired LC startled more intensely than both males at day 0 (when the LC was intact) and control males (saline-injected). 

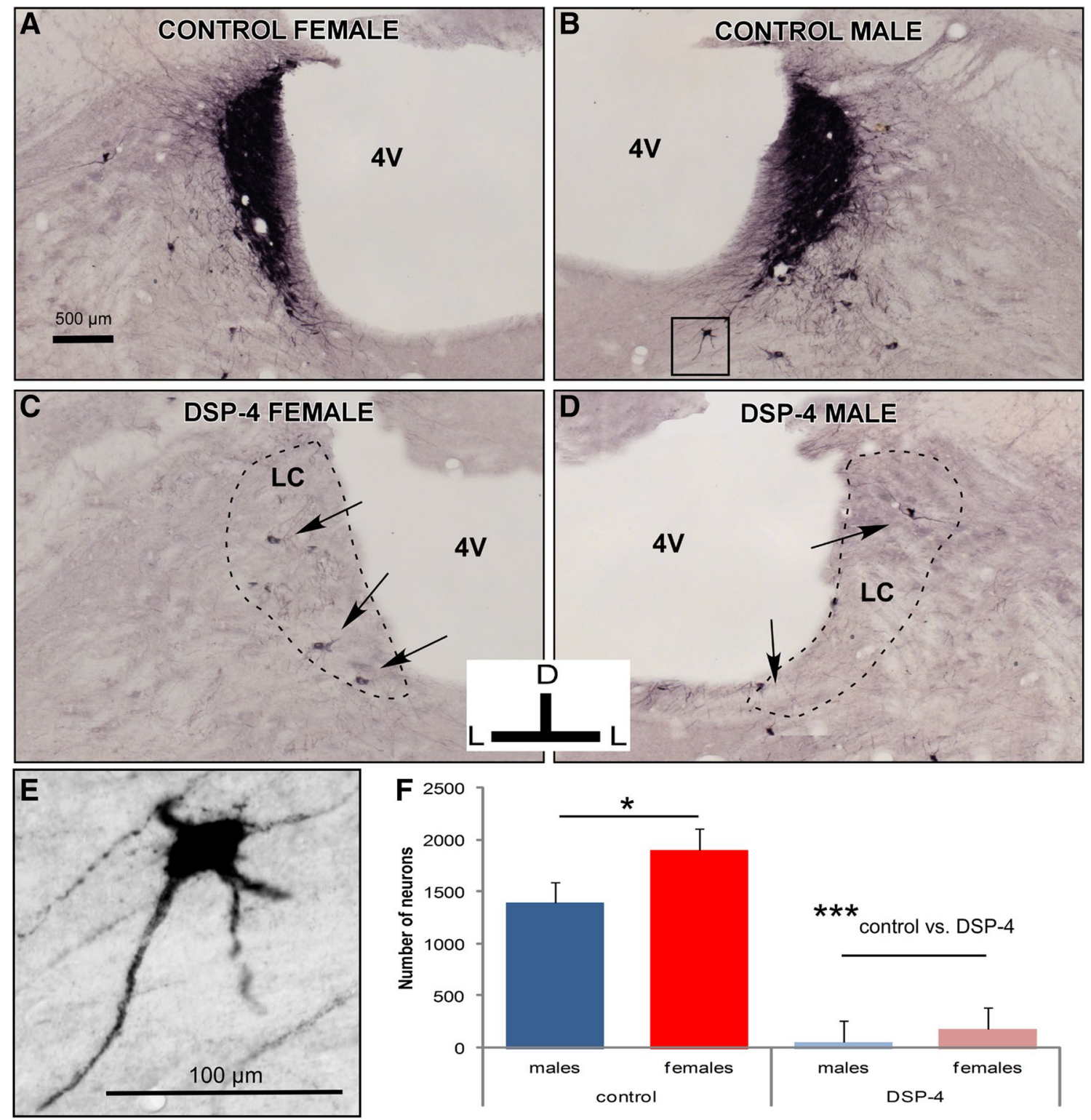

Fig. 1 Effects of DSP-4 injection on the dopamine beta-hydroxylase immunoreactivity of the LC. a, b Photomicrographs of DBH immunoreactivity in female (a) and male (b) control rats. Note there was intense staining. c, d Photomicrographs of DBH immunoreactivity in female (c) and male (d) DSP-4-injected rats. Compared to control (showed in $\mathbf{a}$ and $\mathbf{b}$ ), DBH immunoreactivity was markedly lower in
DSP-4-injected males and females, with just a few scattered positive neurons in the LC (arrows). e Higher magnification of the ventral part of the LC (corresponding to the frame in $\mathbf{b}$ ) shows a multipolar $\mathrm{DBH}$-immunostained neuron. $\mathbf{f}$ Comparison of the number of $\mathrm{DBH}-$ immunolabeled neurons in the LC of both sexes in DSP-4-injected vs. control rats
A noticeable difference in the latency of the ASR depended on sex: females (both control and DSP-4-injected) exhibited shorter values than those from males $\left(F_{(1,89)}=6.78, p<0.05\right)$ (Fig. 3c). Females reacted faster than their male counterparts, but no difference between control and DSP-4 groups of the same sex was found. This points out that those sex-related differences in the response latency were not due to the direct input from the LC.

There was a different level of prepulse inhibition of the ASR response at day 0 depending on the ISI-ranging from $\sim 35$ to $\sim 70 \%$ - (Fig. 3d), with both males and females exhibiting the highest PPI values when ISI $=50 \mathrm{~ms}$. We also found sex differences in PPI at 25, 50, and $150 \mathrm{~ms}$ with males having higher inhibition values $\left(F_{(1,89)}=2.53\right.$, $p<0.05)$; that is, their startle responses were more attenuated due to acoustic prepulses than those of their female counterparts (Fig. 3d). At day 14 post injection, we observed similar results in male and female controls (Fig. 3e), but these differences were absent in DSP-4 groups. Both males and females displayed virtually the 
Fig. 2 Effects of DSP-4 injection on the DBH immunoreactivity of the cochlear root nucleus. a Photomicrograph of the cochlear nerve root immunostained for DBH and CaBP (a marker of CRNs) in a salineinjected rat case. b Higher magnification photomicrograph (corresponding to the frame in a) shows DBH-labeled fibers and terminals (arrowheads) on CaBP-immunolabeled neurons. c Photomicrograph of the cochlear nerve root immunostained for $\mathrm{DBH}$ and $\mathrm{CaBP}$ in a DSP-4-treated case. d Higher magnification photomicrograph (corresponding to the frame in c) shows $\mathrm{CaBP}$-immunolabeled neurons and the absence of DBH-immunolabeled fibers or terminals. $C N$ cochlear nucleus, $c p$ cerebral peduncle, $s p 5$ spinal trigeminal tract, $t z$ trapezoid body

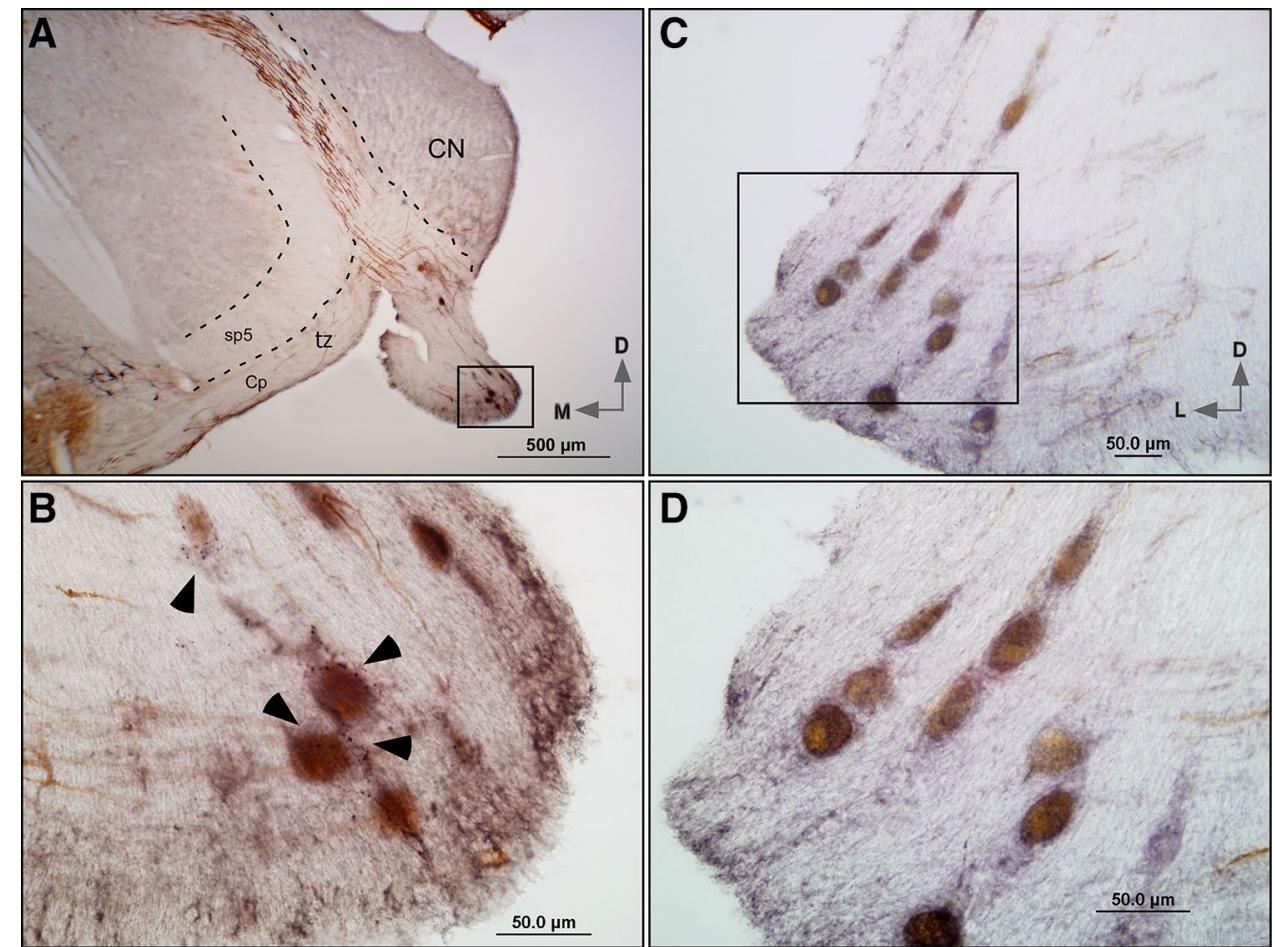

same grade of inhibition (n.s.) for all ISI studied (Fig. 3f). In other words, males and females with impaired LC had similar PPI values, whereas those with the LC intact maintained the sex-linked differences found at day 0 . This fact suggests that the LC may be a key component for explaining PPI differences between males and females.

\section{LC impairment promotes changes in expression of ADR genes in the cochlear nerve root, with differences between sexes}

Our previous study showed that the cochlear nerve root exhibits important gender-specific differences in gene expression of adrenoreceptors (Hormigo et al. 2015). Taking this result into account, we went on to determine if those differences were retained in DSP-4-injected males and females by comparing yield of mRNA encoding ADR subtypes through RT-qPCR assays. Efficiency of the primers is shown in Table 4.

The expression of all ADR subtypes $(\alpha 1 \mathrm{~A}-\mathrm{C}, \alpha 2 \mathrm{~A}-C$, and $\beta 1-3)$ was higher in DSP-4 males compared to that from controls. The most noteworthy levels were found in subtypes $\alpha 1 C$-more than 20 times vs. control$(* * * p<0.001), \quad \alpha 2 \quad A$-near 50 times-(*** $p<0.001)$, and $\beta 3$-around 10 times- $(* * p<0.01)$ (Fig. $4 a-c)$. This incremental phenomenon was not consistent in DSP-4 females. DSP-4-injected females yielded higher mRNA quantity than that from controls only for the subtypes $\alpha 2 \mathrm{~A}$ and $\beta 1$-this one over 130 times $(* * * p<0.001)$ (Fig. 4e, f).
On the other hand, DSP-4 females exhibited lower expression compared to that from control for the ADRs $\alpha 1 A$, $\alpha 1 C, \alpha 2 B$, and $\beta 3$ (Fig. $4 \mathrm{~d}-\mathrm{f}$, respectively). Also, the gene expression of 3 subtypes remained unaltered: $\alpha 1 B, \alpha 2 C$, and $\beta 2$ (Fig. 4d, e, f).

When comparing expression of ADRs in DSP-4-treated males and females, we found males continued to overexpress (higher expression of) all subtypes compared to females (Fig. 5a-c), highlighting that overall, LC-impaired males tended to increase the yield of ADRs in a seemingly consistent manner and this did not happen in females.

In sum, males presented higher expression of all ADR subtypes in the CRNs following impairment of the LC, whereas females displayed upregulations, downregulations, or maintenance of ADR gene expression levels.

\section{Impairment of the LC-NA system generates a decrease in NA levels throughout the brain}

The LC has many diffuse projection targets in both the forebrain and brainstem. The above results drove us to investigate DSP-4 effects not only in the cochlear nerve root, but also in other cerebral areas innervated by the LC. We performed HPLC assays to quantify levels of NA and its metabolite, MHPG, in known LC-innervated brain areas including CRNs, brainstem, inferior colliculus, cerebellum, and prefrontal cortex.

We found an overall decrement in the quantity of NA in DSP-4-injected males and females in all brain regions 

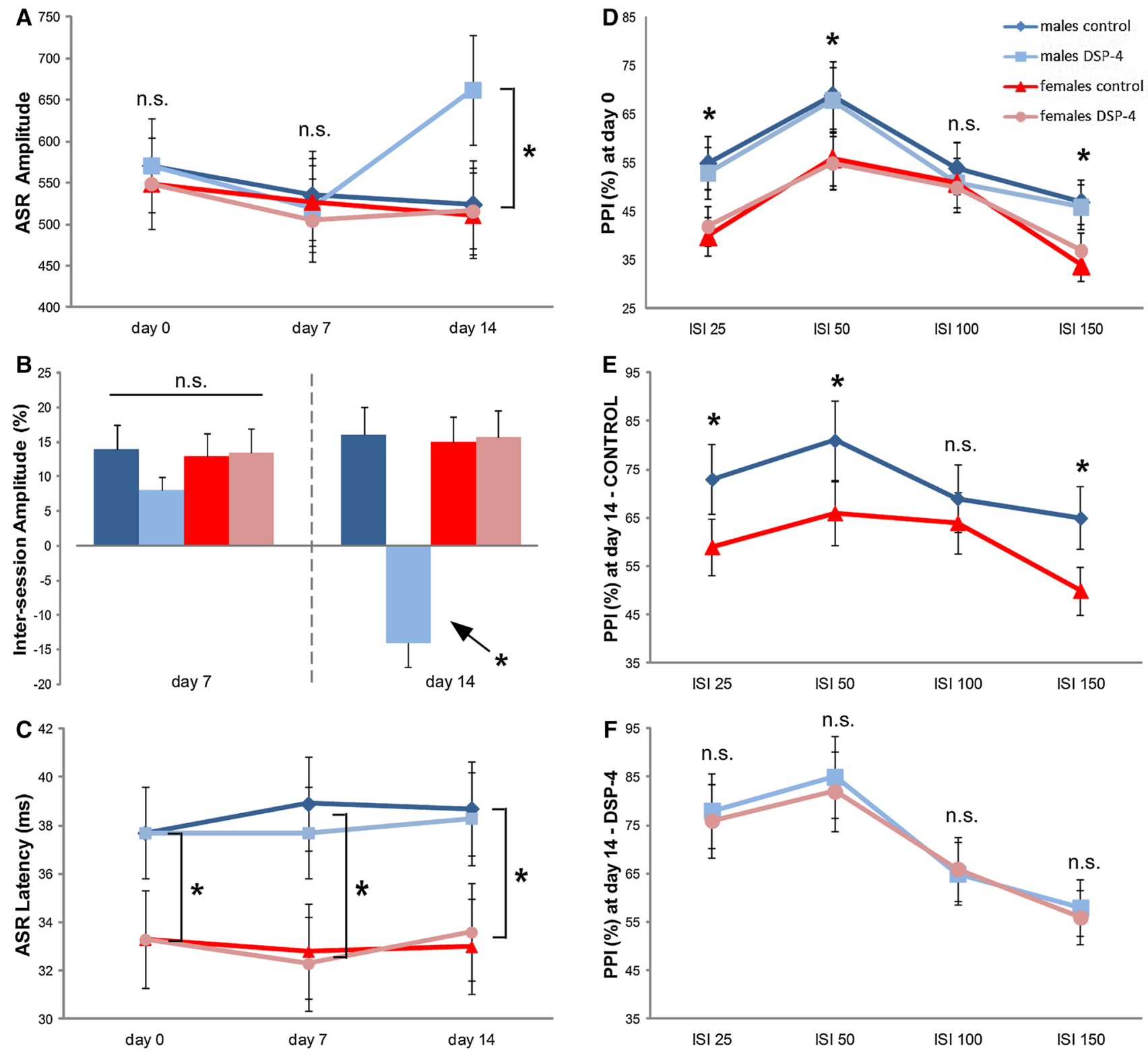

Fig. 3 Effects of LC impairment on the acoustic startle reflex and sensory gating behavioral tests. a Amplitude of the ASR response (arbitrary units). Note that males injected with DSP-4 exhibited the highest values at day 14. b Inter-session ratio of ASR amplitude. All experimental groups showed a decrement of the ASR amplitude compared to day 0, except for DSP-4-injected males that exhibited an increment of the response (arrow). c Latency of the ASR (in ms). There was a sex-linked difference that remained after LC impairment by DSP-4. d Percentage of inhibition related to the different inter-

studied when compared to that from control $(* * p<0.01$ in all regions in both sexes) (Fig. 6a, b), except in the cochlear nerve root of females, which presented unexpected higher levels $(* * p<0.01)$. DSP-4-injected males also presented higher levels of MHPG in the cochlear nerve root and prefrontal cortex, and lower levels in brainstem and cerebellum compared to those from control males (Fig. 6a).

stimulus intervals (ISI) in male and female rats at baseline (day 0), prior to any injection. e Percentage of inhibition related to the different ISI in male and female rats at day 14 post saline injection (control rats). Note the differences by sex at day 0 (d) were maintained at day 14 (e) in controls. f Percentage of inhibition related to the different ISI in male and female rats at day 14 post DSP-4 injection. Note that sex-linked differences observed at day 0 and in control groups disappeared in DSP-4-injected rats

DSP-4-injected females presented lower levels of MHPG in cochlear nerve root, inferior colliculus, cerebellum, and prefrontal cortex compared to those from control females (Fig. 6b). We found no changes in MHPG tissue levels in the inferior colliculus of DSP-4-injected males vs. those from controls (Fig. 6a), and the brainstem of DSP-4-injected females vs. those from controls (Fig. 6b). 
Table 4 Efficiencies of the primers used in the quantitative PCR

As anticipated due to the LC impairment by DSP-4 injection, we found general decrements of NA throughout the brain, along with increments or maintenance of the MHPG levels when compared to those from controls. Interestingly, higher level of NA was observed in the cochlear nerve root of DSP-4-injected females vs. that from control females, and this was not seen in males.

\section{Discussion}

Our results showed a dramatic reduction in DBH immunoreactivity of the LC and of the DBH fiber innervations of the CRNs in DSP-4-injected rats compared to that from controls, suggesting DSP-4 impairs the LC-NA system. In DSP-4-injected rats, both ASR and PPI exhibited sexlinked changes when compared to controls. The most dramatic differences occurred 14 days post injection, when DSP-4 promoted a maximum noradrenergic depletion. ASR amplitude was higher in males when compared to the values before DSP-4 or saline injection. Inter-session ratio of startle amplitude was also modified in males after DSP-4 treatment, while this measure showed no changes in females. PPI differences between male and female seen in controls were not observed in DSP-4-injected rats: LCimpaired males and females had virtually the same inhibition values for all ISIs. DSP-4 administration did not affect latencies of the ASR and PPI paradigms, showing that sexrelated variability in latency remained as in control animals. Expression of ADRs in the cochlear nerve root underwent sex-dependent alterations as well, with males exhibiting upregulations in all subunits. In contrast, females exhibited up-, downregulations, or maintenance, depending on the ADR subunit. Our HPLC analysis showed that NA levels throughout the brain were lower following DSP-4 injection, with the notable exception of the female cochlear nerve root. Lastly, we found higher or preservation of MHPG levels throughout the brain. Our results suggest the LC-CRN projections are morphological correlates of sex differences in the rat's acoustic startle reflex and prepulse inhibition.

\section{Neurotoxic effect of DSP-4 in LC and the noradrenergic innervations of CRNs}

Several studies suggest that the neurotoxic effects of DSP-4 are not uniform in all noradrenergic regions of the brainstem and forebrain (Fritschy and Grzanna 1989; Grzanna et al. 1989; Fritschy et al. 1991; Szot et al. 2010; Ross and Stenfors 2015). Reduction in noradrenergic levels and loss of different subunits of ADRs are more extensive in regions innervated by noradrenergic axons arising from the LC, compared to those provided by other non-coerulean noradrenergic neurons. Distribution of noradrenergic axons with sensitivity to DSP-4 is tightly correlated with the distribution of the LC, and probably the brain regions not affected by DSP-4 receive their noradrenergic input from non-coerulean neurons (Fritschy and Grzanna 1989). Those results support the notion that LC noradrenergic neurons and other noradrenergic non-coerulean neurons establish two different subsystems, which are diverse not only in their projections, but also in the physio-pharmacological properties of their axonal terminals (Fritschy and Grzanna 1989). Injection of DSP-4 is not thought to directly destroy the noradrenergic terminals, but instead causes an intraneuronal injury that leads to accumulation of tyrosine hydroxylase and consequent depletion of NA inside the synaptic terminal (Booze et al. 1988). Noradrenergic terminal markers post DSP-4 injections are transiently altered without loss of LC neurons per se, indicating that DSP-4 is not a neurotoxin that destroys LC neurons. Rather, according to Szot et al. (2010), DSP-4 should be characterized as a compound that has localized effects on particular vesicular proteins in the noradrenergic terminals of the LC, ultimately impairing its output.

The present analysis of the effect of DSP-4 on noradrenergic markers over the CRNs indicates the importance of measuring by-products in several brain regions to verify selectivity of the lesion, as shown in our IHC and HPLC results. Logue et al. (1985) studied effects of DSP-4 on noradrenergic levels in the rat brain and turnover in six different regions: cortex, hippocampus, cerebellum, brainstem, hypothalamus, and LC. In that study, the administration of a $50 \mathrm{mg} / \mathrm{kg}$ dose significantly diminished noradrenergic levels in all regions observed. Apparently, the major reductions were found in cortex 


\begin{tabular}{|ll|ll|}
\hline MALES & $\begin{array}{l}\text { Control-saline } \\
\text { DSP-4 injected }\end{array}$ & FEMALES & $\begin{array}{l}\text { Control-saline } \\
\text { DSP-4 injected }\end{array}$ \\
\hline
\end{tabular}
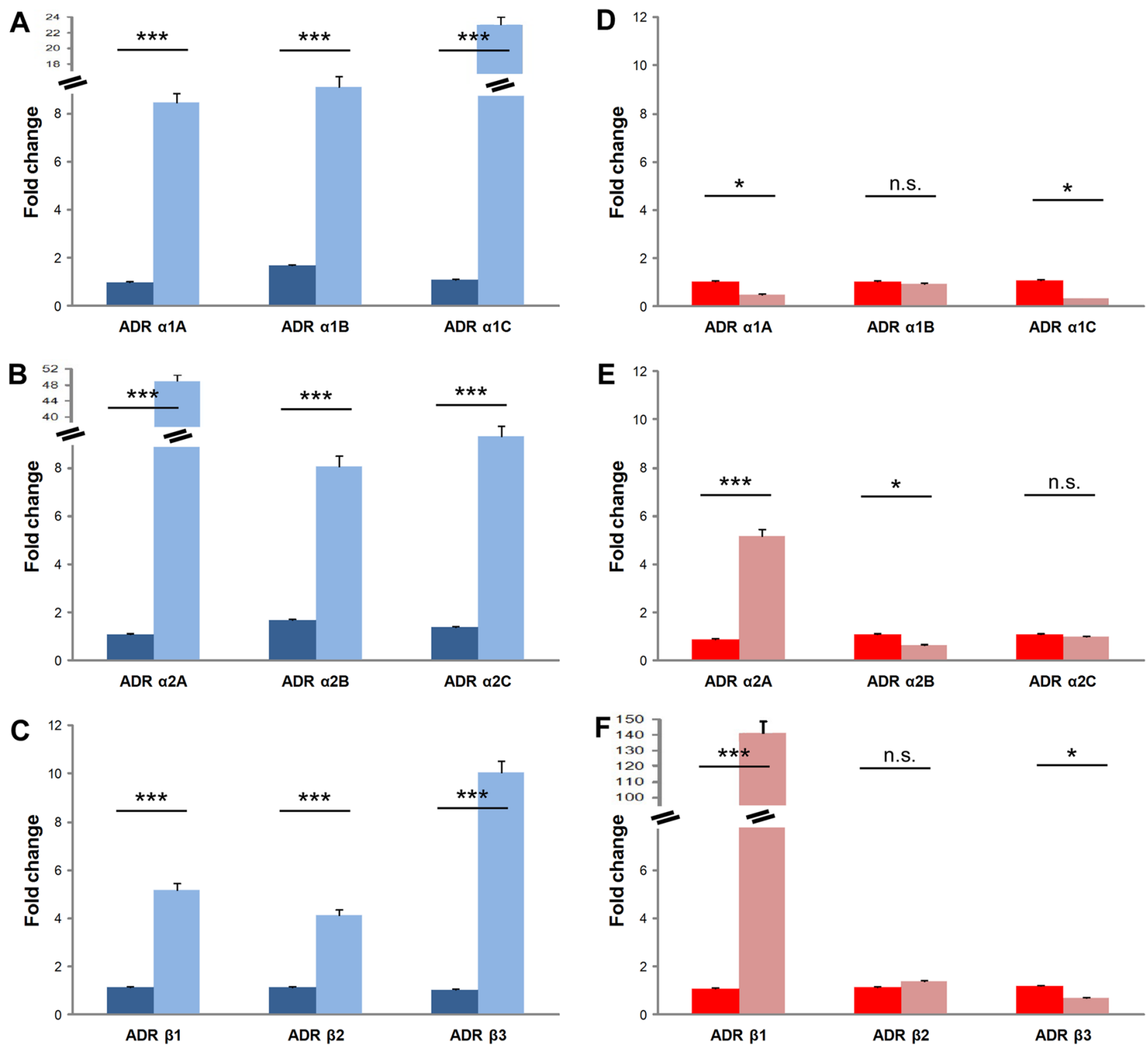

Fig. 4 Adrenergic receptor expression in the cochlear nerve root following DSP-4 injection. a-c Comparison of DSP-4-injected males vs. control. d-f Comparison of DSP-4-injected females vs. control. Note how DSP-4-injected males tended to upregulate all ADR subtype

production when compared to saline-injected controls, whereas DSP4-injected females either upregulated, downregulated, or maintained their expression levels

(up to $86 \%$ ) and hippocampus (91\%). Lower doses provoked a decrement of noradrenergic levels in cerebellum only. Fluorescence histochemical studies confirmed these regional differences and showed almost complete disappearance of the NA nerve terminals in brain regions innervated from the LC (Jonsson et al. 1981). This is in line with our findings that showed decreased levels of NA in LC-targeted areas throughout the brain, with the exception of the female cochlear nerve root, in which we found an increase (not seen in males). This is a rather

surprising finding that might be explained by the existence of non-coerulean noradrenergic projections to the CRNs that might increase their NA production in LCimpaired females, as some kind of compensatory mechanism. In fact, we know that the cochlear nucleus receives projections from the A5 noradrenergic cell group (Da Silva 2015), as well as sparse projections from the A4 and A7 cell groups (Klepper and Herbert 1991). Further research is required to investigate whether these noncoerulean noradrenergic nuclei also send projections to 

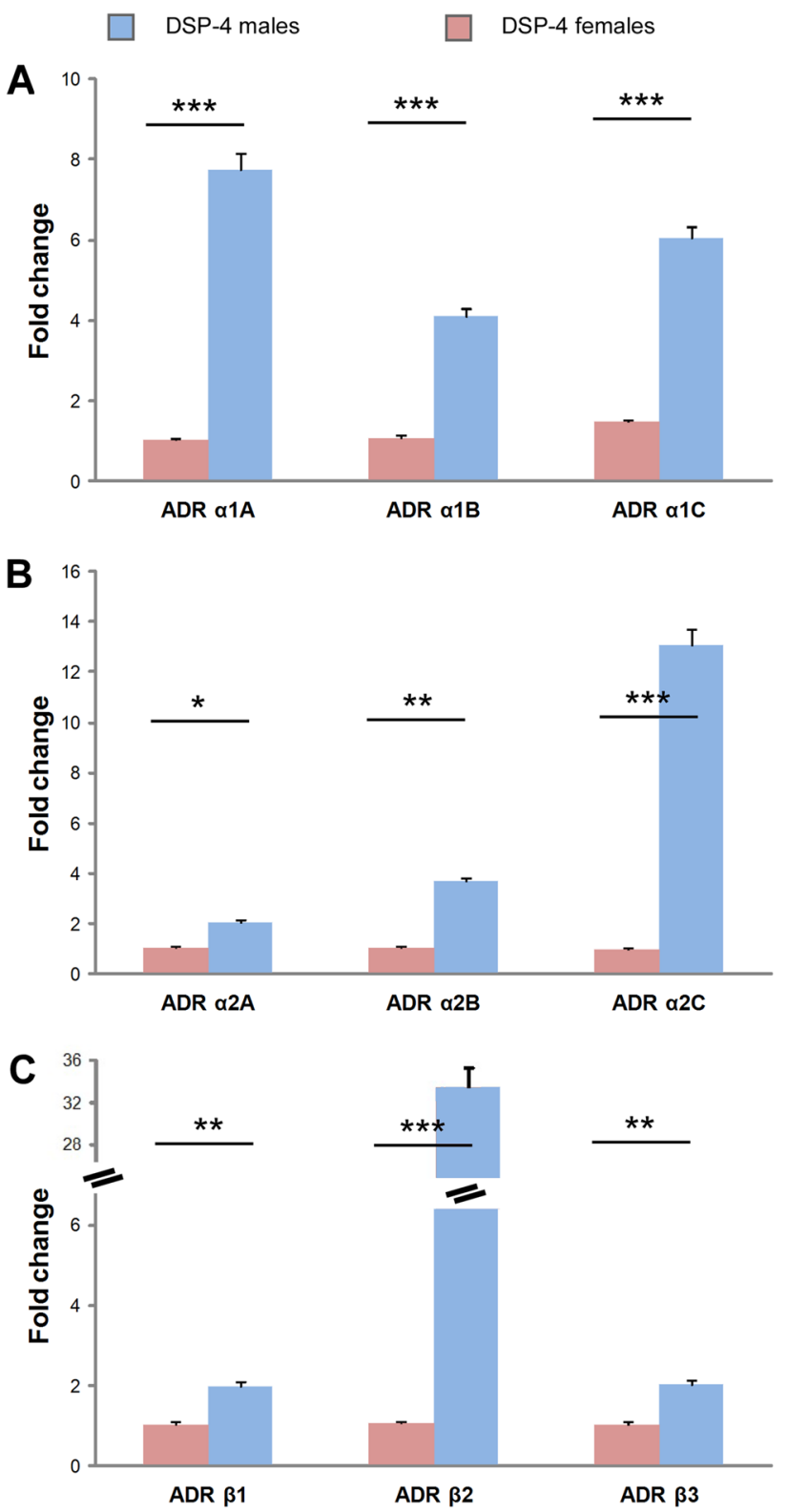

Fig. 5 Adrenergic receptor expression in males and females following DSP-4 injection. a Adrenergic receptor $\alpha 1$ subtypes. b Adrenergic receptor $\alpha 2$ subtype. c Adrenergic receptor $\beta$ subtypes. Note how LC-impaired males tended to present higher yield of ADR production when compared to their female counterparts

the cochlear root nucleus, and if these are in fact taking over functions of an impaired LC. The conclusions of such investigations could potentially have an important impact on drug design for targeting specific brain regions in LC impairment-related diseases such as depression, PTSD, or attention deficit (Bangasser et al. 2016; Timmermans et al. 2013; Neigh et al. 2013; Bangasser and Valentino 2012).
Adrenergic receptor expression profile following LC impairment

We analyzed gene expression of ADRs in the cochlear nerve root to complete the study of the effect on the noradrenergic system following DSP-4 injection. In agreement with earlier findings (Gómez-Nieto et al. 2008b; Hormigo et al. 2015), our data showed that CRNs expressed two main groups of adrenergic receptors, $\alpha$ and $\beta$, and specifically the subtypes $\alpha 1 \mathrm{~A}-\mathrm{B}-\mathrm{C}, \alpha 2 \mathrm{~A}-\mathrm{B}-\mathrm{C}$, and $\beta 1-2-3$. These results were subsequently confirmed by immunolabeling, suggesting that CRNs contain the ADRs that are specific targets of the NA transmitter. Since LC neurons mediate dual effects: neuronal excitation by $\alpha 1$-ADRs and inhibition by $\alpha 2$-ADRs (Szabadi 2013) and CRNs are known to take part in the ASR (Lee et al. 1996; López et al. 1999), the LC-CRN projection might contribute to the modulation of the ASR. Our results further showed that males, in a LCimpaired condition, upregulated the expression of all subtypes of ADRs, whereas females did not do so in the same fashion.

In females, there was an increased expression of the $\alpha 2 \mathrm{~A}$ and $\beta 1$ receptors. ADR $\alpha 2$ subtypes are localized both as prejunctional autoreceptors and postjunctional receptors on axon terminals or dendrites, respectively (Cooper et al. 2003). These subtypes inhibit adenylyl cyclase, suppress voltage-sensitive calcium channels, and activate receptordependent potassium channels. All ADR $\alpha 2$ subtypes inhibit adenylyl cyclase through coupling to members of the Gi/o class of $\mathrm{G}$ proteins. On the other hand, the shorter (418 amino acid) ADR $\beta 2$ is expressed predominantly in the brain, lung, and heart (Guimaraes and Moura 2001). Agonist affinity to $\beta 2$ is modulated by $\mathrm{Zn}^{2+}$ concentration, and in contrast to ADR $\alpha 2 \mathrm{~A}, \beta 2$ signaling is primarily coupled to Gs alpha subunits, stimulating the expression of cAMP and the activation of protein kinase A to regulate L-type $\mathrm{Ca}^{2+}$ channels (Swaminath et al. 2003; Li et al. 2004).

Our results also showed females exhibited a decrease in the production of the $\alpha 1$ subtypes. The ADR $\alpha 1$ subtypes are found in a wide variety of tissues and have been shown to be involved in the regulation of blood pressure during changes in vascular tone and cardiac output. These subtypes are postsynaptic receptors (Cooper et al. 2003); NA can increase nitric oxide synthase levels in the central nervous system by activating ADR $\alpha 1$, which may indirectly suppress the release of luteinizing hormone, androgens, estrogen, and progesterone. (Dong et al. 1999; Vicentic et al. 2002).

Taking into account these cascades and the diversity of ADR expression during a LC-impaired condition, we suggest there might be a biochemical background for explaining the different responses found during the sensory 
A

DSP-4 injected males

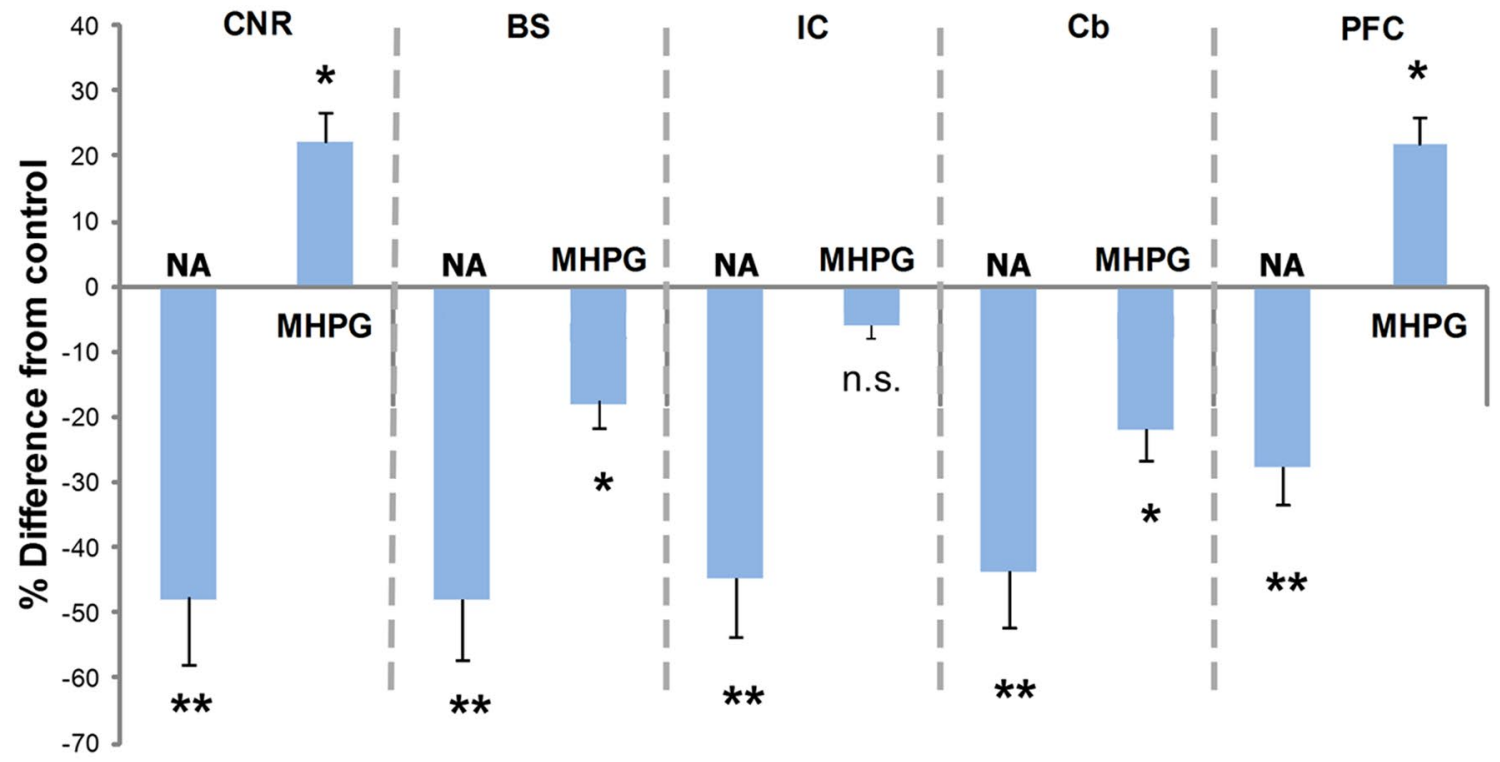

B DSP-4 injected females

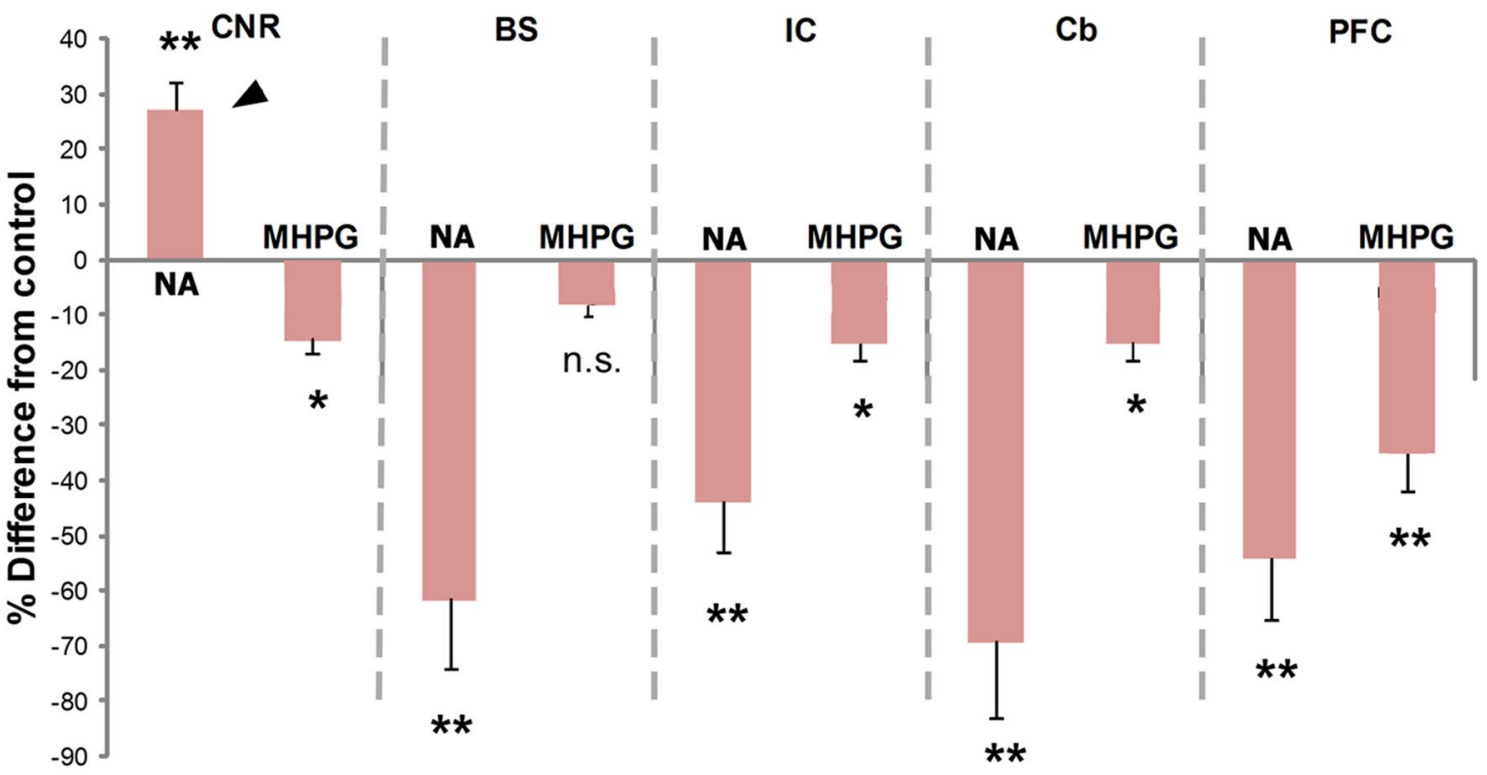

Fig. 6 Catecholaminergic compounds NA and MHPG level changes after DSP-4 injection. a Males. b Females. Regions studied were known LC-innervated target structures throughout the brain: cochlear nerve root (CNR), brainstem (BS), inferior colliculus (IC), cerebellum $(\mathrm{Cb})$, and prefrontal cortex (PFC). Following LC impairment,
NA was found in lower amounts in every structure, except for the cochlear nerve root of females (arrow), whereas MHPG tended to be found either in higher amounts, or same levels, when compared to their saline-injected controls gating tests between males and females. How noradrenergic inputs modulate the ASR circuit is not well known since their effects depend on the receptor subtypes they act upon (Davis et al. 1989; Bylund 1992; Wamsley et al. 1992; Stevens et al. 1994; Carasso et al. 1998; Sallinen et al. 1998; Kable et al. 2000). Besides, the LC neurons are under auto-regulation via inhibitory somatodendritic ADR $\alpha 2$ subtypes that dampen neuronal firing as activity increases (Huang et al. 2012). Therefore, the LC activity could be modified by experimental manipulation of central $\alpha 2$-adrenoceptors, which in turn could lead to changes in sensory gating processes. While drugs targeted at ADR $\alpha 2$ 
are likely to have a direct effect on the LC activity, a number of drugs may modify the LC activity indirectly by modulating the excitatory and inhibitory inputs to the LC. Our study provides the first evidence along this line. However, further experiments such as administration of different pharmacological agonists and/or antagonists of ADRs during in vivo and behavioral experiments are needed to clarify the specific roles of (1) the LC, (2) the different ADRs subtypes, and (3) the particular noradrenergic modulation in the ASR circuit. These pharmacological experiments may shed light on how the internal cellular machinery regulates biochemical cascades implemented by activation/inactivation of different ADRs during sensory gating processes.

\section{Sex-dependent LC roles in startle reflex circuitry and sensory gating neurological processes}

An interesting feature of the ASR and its prepulse inhibition is that humans and rats show marked sexual differences. Both behavioral paradigms are greater in males than in females as described in this report and the literature (Lehmann et al. 1999; Braff et al. 2001; Aasen et al. 2005). However, little is known about the neural mechanisms underlying these sex-linked differences. Our study proposes the LC as an important structure that partakes in the modulation of the ASR via LC-CRN noradrenergic projections and that defines differences between males and females, given the LC anatomical dimorphism. We also support the hypothesis that the CRNs are the first brainstem neurons that participate not only in the initiation of the acoustic startle reflex (López et al. 1999) but also in its modulation, as seen in this study and elsewhere (Gómez-Nieto et al. 2008a, b, 2014b; Hormigo et al. 2015). Furthermore, we reported that CRNs exhibit important gender-specific differences in gene expression of ADRs after LC impairment. This result together with the differences found in the distribution of the LC neuronal density between males and females (Hormigo et al. 2015) may help to explain the gender differences observed in behavioral paradigms (Lehmann et al. 1999).

Prior studies also noted the importance of the CRNs in the modulation of the ASR (Gómez-Nieto et al. 2008a, b, 2010, 2014b). These studies focused on analyzing the afferents and provided molecular and electrophysiological evidence of their role in the modulation and inhibition of the CRN response after auditory prepulse stimulation. Our current study increases the knowledge of the CRN inputs, suggesting that the coerulean noradrenergic system in the CRNs might account for the neuronal mechanism underlying modulation of the ASR, and explain part of their sexually dimorphic differences as well. Reduction of the startle response after bilateral chemical lesions of the LC also supports its role in the modulation of behavioral reactivity to sensory stimulation (Adams and Geyer 1981). Our results showed that LC-impaired males had a disruption in ASR amplitude. 14 days after DSP-4 injection, LCimpaired males showed a large increase in amplitude not seen in females. This result suggests that the LC is acting differently in males than females regarding ASR circuitry, with males showing a clear effect. Specifically, we hypothesize the LC might be maintaining an attention threshold that allows ASR to be triggered within a normal range of amplitude. However, when LC is impaired, this attention threshold is disrupted and the ASR is triggered with abnormally higher amplitude in males. This feature was not seen in females, which maintained normal amplitude and inter-session startle amplitude levels. To our understanding, this finding implies that attentional processes are subjected to sex-related qualities, with males relying mainly on the LC whereas females may rely on other sources besides the LC. Throughout the brain in males, DSP-4 promoted lower levels of NA, which subsequently might have led to a higher expression of all ADR subtypes in the cochlear nerve root--shown in our results-as a plasticity mechanism to maximize the collection of the lowered NA levels. This is consistent with Heal et al. (1993), who described a rapid proliferation of the $\alpha 2$ postsynaptic adrenoceptors due to decreased synaptic NA levels 15 days after injecting $100 \mathrm{mg} / \mathrm{kg}$ of DSP-4 IP in rats. We suggest that at the same time, this may be contributing to a lower inhibition of the voltage-sensitive $\mathrm{Ca}^{2+}$ channels (Martire et al. 1995), which in turn may cause a higher ASR intensity as seen in our results.

On the other hand, our results also showed sex-linked differences in PPI values in control, in accordance with the literature (Lehmann et al. 1999; Braff et al. 2001; Aasen et al. 2005), with males exhibiting higher inhibition values compared to females. Interestingly, after LC impairment, we did not observe such differences anymore. That is, following LC impairment, both males and females exhibited the same inhibition values for all ISIs tested. Hormigo et al. (2015) showed that CRNs receive direct LC inputs, indicating that there are at least two efferent pathways through which LC could modulate the ASR. The LC noradrenergic axons contact the primary ASR at the initial and final relays of the primary acoustic startle circuit. On the first relay, CRNs contain noradrenergic receptors $(\alpha 1$, $\alpha 2, \beta 2$-ADRs) that are sufficient to modulate the startle response. On the final relay, motoneurons in the spinal cord are under the influence of excitatory projections from the LC via $\alpha 1$-ADRs (Funk et al. 2000; Heckman et al. 2009; Noga et al. 2011; Szabadi 2012). The activation of LC neuronal firing elevates NA release in LC terminal regions that results in a disruption of the PPI (Berridge and Abercrombie 1999; Alsene and Bakshi 2011). Our study provides strong evidence of coerulean NA release in the CRNs, and 
therefore the LC-CRN projections might be part of the startle reflex modulation pathways that are altered after experimental manipulation of the LC.

However, there may also be other output pathways through which the LC is connected to the PPI-mediating circuitry as well. One of them is the coerulean projection to the pedunculopontine tegmental nucleus that modulates the primary startle circuit at the level of the pontine reticular nucleus (Jones 1991; Fendt et al. 2001; Alsene and Bakshi 2011). Another one is the coerulean projections to auditory nuclei that are involved in the prepulse inhibition such as the inferior colliculus (Hormigo et al. 2012; Yeomans et al. 2006) and the ventral nucleus of the trapezoid body, which modulates CRN activity (Mulders and Robertson 2001; Gómez-Nieto et al. 2008a, 2014b). In sum, the existence of direct projections from the LC to the CRNs might establish the LC as an essential structure in the neuronal substrates underlying survival and escape behavioral paradigms in response to unexpected loud sounds.

Acknowledgements The authors declare no conflicts of interest, financial or otherwise. The study was supported in part by the Spanish Grants BFU2010-17754 (MICINN) and SAF2016-78898-C22R (MINECO), and by the São Paulo State Research Foundation FAPESP proc. 2008/02771-6. The authors also thank Sonia Hernández for technical support in the experiments; and Brian Swoyer and Kristiina Hormigo for language editing services.

\section{Compliance with ethical standards}

Conflict of interest This study was supported in part by the Spanish Grants BFU2010-17754 (MICINN) and SAF2016-78898-C2-2R (MINECO) to DEL, and by the São Paulo State Research Foundation FAPESP proc. 2008/02771-6 to JACHJ. The funders did not take part of this study whatsoever, and the authors declare no conflicts of interest, financial or otherwise.

\section{References}

Aasen I, Kolli L, Kumari V (2005) Sex effects in prepulse inhibition and facilitation of the acoustic startle response: implications for pharmacological and treatment studies. J Psychopharmacol 19(1):39-45

Adams LM, Geyer MA (1981) Effects of 6-hydroxydopamine lesions of locus coeruleus on startle in rats. Psychopharmacology (Berl) 73(4):394-398

Alsene KM, Bakshi VP (2011) Pharmacological stimulation of locus coeruleus reveals a new antipsychotic-responsive pathway for deficient sensorimotor gating. Neuropsychopharmacology 36(8):1656-1667

Asakura M, Nagashima H, Fujii S, Sasuga Y, Misonoh A, Hasegawa $\mathrm{H}$, Osada K (2000) Influences of chronic stress on central nervous systems. Nihon Shinkei Seishin Yakurigaku Zasshi 20(3):97-105

Aston-Jones G, Bloom FE (1981) Activity of norepinephrine-containing locus coeruleus neurons in behaving rats anticipates fluctuations in sleep-waking cycle. J Neurosci 1(8):876-886
Aston-Jones G, George P (2004) Chap. 11: Locus Coeruleus, A5 and A7 Noradrenergic Cell Groups. In: The rat nervous system Third(Edn), Academic Press, Burlington, pp 259-294

Aston-Jones G, Akaoka H, Charléty P, Chouvet G (1991) Serotonin selectively attenuates glutamate-evoked activation of noradrenergic locus coeruleus neurons. J Neurosci 11(3):760-769

Aston-Jones G, Rajkowski J, Cohen J (1999) Role of locus coeruleus in attention and behavioral flexibility. Biol Psychiatry 46(9):1309-1320 (Review)

Bakker MJ, van Dijk JG, van den Maagdenberg AM, Tijssen MA (2006) Startle syndromes. Lancet Neurol 5(6):513-524 (Review)

Bangasser DA, Valentino RJ (2012) Sex differences in molecular and cellular substrates of stress. Cell Mol Neurobiol 32(5):709-723. doi:10.1007/s10571-012-9824-4

Bangasser DA, Zhang X, Garachh V, Hanhauser E, Valentino RJ (2011) Sexual dimorphism in locus coeruleus dendritic morphology: a structural basis for sex differences in emotional arousal. Physiol Behav 103(3-4):342-351

Bangasser DA, Wiersielis KR, Khantsis S. (2016) Sex differences in the locus coeruleus-norepinephrine system and its regulation by stress. Brain Res 1641(Pt B):177-188. doi:10.1016/j. brainres.2015.11.021

Baudrie V, Tulen JH, Blanc J, Elghozi JL (1997) Autonomic components of the cardiovascular responses to an acoustic startle stimulus in rats. J Auton Pharmacol 17(5):303-309

Bell RL, Rodd ZA, Hsu CC, Lumeng L, Murphy JM, McBride WJ (2003) Amphetamine-modified acoustic startle responding and prepulse inhibition in adult and adolescent alcoholpreferring and -nonpreferring rats. Pharmacol Biochem Behav 75(1):163-171

Berridge CW, Abercrombie ED (1999) Relationship between locus coeruleus discharge rates and rates of norepinephrine release within neocortex as assessed by in vivo microdialysis. Neuroscience 93(4): 1263-1270

Booze RM, Hall JA, Cress NM, Miller GD, Davis JN (1988) DSP-4 treatment produces abnormal tyrosine hydroxylase immunoreactive fibers in rat hippocampus. Exp Neurol 101(1):75-86

Bradford MM (1976) A rapid and sensitive method for the quantitation of microgram quantities of protein utilizing the principle of protein-dye binding. Anal Biochem 72:248-254

Braff DL, Geyer MA (1990) Sensorimotor gating and schizophrenia. Human and animal model studies. Arch Gen Psychiatry 47(2):181-188

Braff D, Stone C, Callaway E, Geyer M, Glick I, Bali L (1978) Prestimulus effects on human startle reflex in normals and schizophrenics. Psychophysiology 15(4):339-343

Braff DL, Geyer MA, Swerdlow NR (2001) Human studies of prepulse inhibition of startle: normal subjects, patient groups, and pharmacological studies. Psychopharmacology (Berl) 156(2-3):234-258

Burns MJ, Nixon GJ, Foy CA, Harris N (2005) Standardisation of data from real-time quantitative PCR methods-evaluation of outliers and comparison of calibration curves. BMC Biotechnol 7(5):31. doi:10.1186/1472-6750-5-31

Bylund DB (1992) Subtypes of alpha 1- and alpha 2-adrenergic receptors. FASEB J 6(3):832-839 (Review)

Carasso BS, Bakshi VP, Geyer MA (1998) Disruption in prepulse inhibition after alpha-1 adrenoceptor stimulation in rats. Neuropharmacology 37(3):401-404

Castellano O, Moscoso A, Riolobos AS, Carro J, Arji M, Molina V, López DE, Sancho C (2009) Chronic administration of risperidone to healthy rats: a behavioural and morphological study. Behav Brain Res 205(2):488-498. doi:10.1016/j.bbr.2009.08.002

Cooper JR, Bloom FE, Roth RH (2003) The biochemical basis of neuropharmacology, 6th edn. Oxford U., Oxford 
Couto LlB, Moroni CRr, Ferreira ClMdR, Elias-Filho DH, Parada CAl, Pelao IR, Coimbra NC (2006) Descriptive and functional neuroanatomy of locus coeruleus-noradrenaline-containing neurons involvement in bradykinin-induced antinociception on principal sensory trigeminal nucleus. J Chem Neuroanat 32(1):28-45

Da Silva AV (2015) Origem de aferências monoaminérgicas e cartérgicas ao circuito elementar do reflexo auditivo de sobressalto. (PhD thesis). Insituto de Biociências de Botucatu, Departamento de Anatomia, UNESP, Botucatu, p 133. http://athena.biblioteca.unesp.br/F? func $=$ direct\&local_base $=$ UEP01\&doc_number $=000865781$

Davis M, Commissaris RL, Yang S, Wagner KR, Kehne JH, Cassella JV, Boulis NM (1989) Spinal vs. supraspinal sites of action of the alpha-2-adrenergic agonists clonidine and ST-91 on the acoustic startle reflex. Pharmacol Biochem Behav 33(1):233-240

Dong L-W, Yang J, Tong L-J, Tang C, Liu M-S (1999) Transcriptional regulation of alpha-1-adrenoceptor gene in the rat liver during different phases of sepsis. Biochim Biophys Acta Mol Basis Dis 1453(2):207-215.

Fendt M, Li L, Yeomans JS (2001) Brain stem circuits mediating prepulse inhibition of the startle reflex. Psychopharmacology (Berl) 156(2-3):216-224

Foote SL, Aston-Jones G, Bloom FE (1980) Impulse activity of locus coeruleus neurons in awake rats and monkeys is a function of sensory stimulation and arousal. Proc Natl Acad Sci USA 77(5):3033-3037

Fritschy JM, Grzanna R (1989) Immunohistochemical analysis of the neurotoxic effects of DSP-4 identifies two populations of noradrenergic axon terminals. Neuroscience 30(1):181-197

Fritschy JM, Grzanna R, Pompeiano CDBaO (1991) Chapter 20 Selective effects of DSP-4 on locus coeruleus axons: are there pharmacologically different types of noradrenergic axons in the central nervous system? In: Progress in brain research, Elsevier, Amsterdam, pp 257-268

Funk GD, Parkis MA, Selvaratnam SR, Robinson DM, Miles GB, Peebles KC (2000) Synaptic control of motoneuron excitability inrodents:from monthstomilliseconds. Clin Exp Pharmacol Physiol 27:120-125

Gómez-Nieto R, Rubio ME, López DE (2008a) Cholinergic input from the ventral nucleus of the trapezoid body to cochlear root neurons in rats. J Comp Neurol 506(3):452-468

Gómez-Nieto R, Horta-Junior JAC, Castellano O, Herrero-Turrión MJ, Rubio ME, López DE (2008b) Neurochemistry of the afferents to the rat cochlear root nucleus: Possible synaptic modulation of the acoustic startle. Neuroscience 154(1):51-64

Gómez-Nieto R, Horta-Junior JAC, Castellano O, Sinex DG, López DE (2010) Auditory prepulse inhibition of neuronal activity in the rat cochlear root nucleus. In: López-Poveda EA, Palmer AR, Meddis R (eds.) The neurophysiological bases of auditory perception, pp 79-90

Gómez-Nieto R, Horta-Júnior JAC, Castellano O, Millian-Morell L, Rubio ME, López DE (2014a) Origin and function of short-latency inputs to the neural substrates underlying the acoustic startle reflex. Front Neurosci 8:216. doi:10.3389/ fnins.2014.00216

Gómez-Nieto R, Sinex DG, C Horta-Junior JD, Castellano O, Herrero-Turrion JM, López DE (2014b) A fast cholinergic modulation of the primary acoustic startle circuit in rats. Brain Struct Funct 219(5):1555-1573. doi:10.1007/s00429-013-0585-8.

Grant SJ, Aston-Jones G, Redmond DE Jr (1988) Responses of primate locus coeruleus neurons to simple and complex sensory stimuli. Brain Res Bull 21(3):401-410

Grzanna R, Berger U, Fritschy JM, Geffard M (1989) Acute action of DSP-4 on central norepinephrine axons: biochemical and immunohistochemical evidence for differential effects. J Histochem Cytochem 37(9):1435-1442
Guimaraes S, Moura D (2001) Vascular adrenoceptors: an update. Pharmacol Rev 53(2):319-356

Heal DJ, Butler SA, Prow MR, Buckett WR (1993) Quantification of presynaptic alpha-2-adrenoceptors in rat brain after shortterm DSP-4 lesioning. Eur J Pharmacol 249(1):37-41

Heckman CJ, Mottram C, Quinlan K, Theiss R, Schuster J (2009) Motoneuron excitability: the importance of neuromodulatory inputs. Clin Neurophysiol 120:2040-2054

Hoffman HS, Ison JR (1980) Reflex modification in the domain of startle: I. Some empirical findings and their implications for how the nervous system processes sensory input. Psychol Rev 87(2):175-189

Hormigo S, E Horta, Junior JdAdC, Gómez-Nieto R, López Garcia DE (2012) The selective neurotoxin DSP-4 impairs the noradrenergic projections from the locus coeruleus to the inferior colliculus in rats. Front Neural Circuits 6:41. doi:10.3389/ fncir.2012.00041

Hormigo S, Gómez-Nieto R, Castellano O, Herrero-Turrion MJ, López DE, E Horta, Junior JdAdC (2015) The noradrenergic projection from the locus coeruleus to the cochlear root neurons in rats. Brain Struct Funct, 220(3):1477-1496. doi:10.1007/s00429-014-0739-3

Huang H-P, Zhu F-P, Chen X-W, Xu Z-QD, Zhang CX, Zhou Z (2012) Physiology of quantal norepinephrine release from somatodendritic sites of neurones in locus coeruleus. Front Mol Neurosci 5:1-5. doi:10.3389/fnmol.2012.00029

Jones BE (1991) Noradrenergic locus coeruleus neurons: their distant connections and their relationship to neighboring (including cholinergic and GABAergic) neurons of the central gray and reticular formation. Prog Brain Res 88:15-30

Jonsson G, Hallman H, Ponzio F, Ross S (1981) DSP4 ( $N$-(2-chloroethyl)- $N$-ethyl-2-bromobenzylamine-a useful denervation tool for central and peripheral noradrenaline neurons. Eur J Pharmacol 72(2-3):173-188

Justus AN, Finn PR (2007) Startle modulation in non-incarcerated men and women with psychopathic traits. Pers Individ Dif 43(8):2057-2071.

Kable JW, Murrin LC, Bylund DB (2000) In vivo gene modification elucidates subtype-specific functions of alpha(2)-adrenergic receptors. J Pharmacol Exp Ther 293(1):1-7

Keay KA, Redgrave P, Dean P (1988) Cardiovascular and respiratory changes elicited by stimulation of rat superior colliculus. Brain Res Bull 20(1):13-26

Klepper A, Herbert H (1991) Distribution and origin of noradrenergic and serotonergic fibers in the cochlear nucleus and inferior colliculus of the rat. Brain Res 557(1-2):190-201

Landis C, Hunt WA (1939) The startle pattern. Ferrar \& Rinehart, New York

Lee Y, López DE, Meloni EG, Davis M (1996) A primary acoustic startle pathway: obligatory role of cochlear root neurons and the nucleus reticularis pontis caudalis. J Neurosci 16(11):3775-3789

Lehmann J, Pryce CR, Feldon J (1999) Sex differences in the acoustic startle response and prepulse inhibition in Wistar rats. Behav Brain Res 104(1-2):113-117

Li F, De Godoy Mr, Rattan S (2004) Role of adenylate and guanylate cyclases in beta1-, beta2-, and beta3-adrenoceptormediated relaxation of internal anal sphincter smooth muscle. J Pharmacol Exp Ther 308(3):1111-1120

Li L, Du Y, Li N, Wu X, Wu Y (2009) Top-down modulation of prepulse inhibition of the startle reflex in humans and rats. Neurosci Biobehav 33(8):1157-1167.

Livak KJ, Schmittgen TD (2001) Analysis of relative gene expression data using real-time quantitative PCR and the 2alpha-CT method. Methods 25(4):402-408 
Logue MP, Growdon JH, Coviella ILG, Wurtman RJ (1985) Differential effects of DSP-4 administration on regional brain norepinephrine turnover in rats. Life Sci 37(5):403-409

López DE, Saldana E, Nodal FR, Merchán MA, Warr WB (1999) Projections of cochlear root neurons, sentinels of the auditory pathway in the rat. J Comp Neurol 415(2):160-174

Ma S, Mifflin SW, Cunningham JT, Morilak DA (2008) Chronic intermittent hypoxia sensitizes acute hypothalamic-pituitary adrenal stress reactivity and Fos induction in the rat locus coeruleus in response to subsequent immobilization stress. Neuroscience 154(4):1639-1647

Martire M, Pistritto G, Mores N, Agnati LF, Fuxe K (1995) Presynaptic A2-adrenoceptors and neuropeptide $\mathrm{Y}$ Y2 receptors inhibit $[3 \mathrm{H}]$ noradrenaline release from rat hypothalamic synaptosomes via different mechanisms. Neurosci Lett 188(1):9-12

Miao-Kun S (1995) Central neural organization and control of sympathetic nervous system in mammals. Prog Neurobiol 47(3):157-233

Molina V, Montes C, Tamayo P, Villa R, Isabel Osuna M, Perez J, Sancho C, López-Albuquerque T, Cardoso A, Castellano O, López DE (2009) Correlation between prepulse inhibition and cortical perfusion during an attentional test in schizophrenia. A pilot study. Prog Neuropsychopharmacol Biol Psychiatry 33(1):53-61

Mulders WH, Robertson D (2001) Origin of the noradrenergic innervation of the superior olivary complex in the rat. J Chem Neuroanat 21(4):313-322

Neigh GN, Ritschel LA, Kilpela LS, Harrell CS, Bourke CH (2013) Translational reciprocity: bridging the gap between preclinical studies and clinical treatment of stress effects on the adolescent brain. Neuroscience 249:139-153. doi:10.1016/j. neuroscience.2012.09.075

Noga BR, Johnson DM, Riesgo MI, Pinzon A (2011) Locomotoractivated neuronsof the cat. II. Noradrenergic innervation and colocalization with NE $\alpha 1 \mathrm{a}$ and NE $\alpha 2 \mathrm{~b}$ receptors in the thoracolumbar spinal cord. J Neurophysiol 105(4):1835-1849

Page ME, Akaoka H, Aston-Jones G, Valentino RJ (1992) Bladder distention activates noradrenergic locus coeruleus neurons by an excitatory amino acid mechanism. Neuroscience 51(3):555-563

Paxinos G, Watson C (2005) The rat brain in stereotaxic coordinates: the new coronal set-161 diagrams, 5th edn. Academic Press, San Diego

Pinos H, Collado P, Rodriguez-Zafra M, Rodriguez C, Segovia S, Guillamon A (2001) The development of sex differences in the locus coeruleus of the rat. Brain Res Bull 56(1):73-78

Rosario LA, Abercrombie ED (1999) Individual differences in behavioral reactivity: correlation with stress-induced norepinephrine efflux in the hippocampus of Sprague-Dawley rats. Brain Res Bull 48(6):595-602

Ross SB (1985) DSP4 and behavioural experiments. Trends Pharmacol Sci 6:237-237

Ross SB, Stenfors C (2015) DSP4, a selective neurotoxin for the locus coeruleus noradrenergic system. A review of its mode of action. Neurotox Res 27(1):15-30. doi:10.1007/s12640-014-9482-Z (Review)

Ross SB, Johansson JG, Lindborg B, Dahlbom R (1973) Cyclizing compounds. I. Tertiary $N$-(2-bromobenzyl)- $N$-haloalkylamines with adrenergic blocking action. Acta Pharm Suec 10(1):29-42

Sallinen J, Haapalinna A, Viitamaa T, Kobilka BK, Scheinin M (1998) $d$-amphetamine and $l$-5-hydroxytryptophan-induced behaviours in mice with genetically-altered expression of the alpha-2C-adrenergic receptor subtype. Neuroscience 86(3):959-965

Sara SJ, Segal M (1991) Plasticity of sensory responses of locus coeruleus neurons in the behaving rat: implications for cognition. Prog Brain Res 88:571-585
Schmittgen TD, Livak KJ (2008) Analyzing real-time PCR data by the comparative $\mathrm{C}(\mathrm{T})$ method. Nat Protoc 3(6):1101-1108

Singewald N, Zhou G-Y, Schneider C (1995) Release of excitatory and inhibitory amino acids from the locus coeruleus of conscious rats by cardiovascular stimuli and various forms of acute stress. Brain Res 704(1):42-50

Stevens DR, McCarley RW, Greene RW (1994) The mechanism of noradrenergic alpha 1 excitatory modulation of pontine reticular formation neurons. J Neurosci 14(11 Pt 1):6481-6487

Sullivan RM, Wilson DA, Lemon C, Gerhardt GA (1994) Bilateral 6-OHDA lesions of the locus coeruleus impair associative olfactory learning in newborn rats. Brain Res 643(1-2):306-309

Swaminath G, Lee TW, Kobilka B (2003) Identification of an allosteric binding site for $\mathrm{Zn}^{2+}$ on the beta- 2 adrenergic receptor. $\mathrm{J}$ Biol Chem 278(1):352-356

Swerdlow NR, Geyer MA (1998) Using an animal model of deficient sensorimotor gating to study the pathophysiology and new treatments of schizophrenia. Schizophr Bull 24(2):285-301

Swerdlow NR, Braff DL, Geyer MA (2000) Animal models of deficient sensorimotor gating: what we know, what we think we know, and what we hope to know soon. Behav Pharmacol 11(3-4):185-204

Swerdlow NR, Hanlon FM, Henning L, Kim YK, Gaudet I, Halim ND (2001) Regulation of sensorimotor gating in rats by hippocampal NMDA: anatomical localization. Brain Res 898(2):195-203 (PubMed PMID: 11306005)

Szabadi E (2012) Modulation of physiological reflexes by pain: role of the locus coeruleus. Front Integr Neurosci 6:94 doi:10.3389/ fnint.2012.00094.

Szabadi E (2013) Functional neuroanatomy of the central noradrenergic system. J Psychopharmacol 27(8):659-693

Szot P, Miguelez C, White SS, Franklin A, Sikkema C, Wilkinson CW, Ugedo L, Raskind MA (2010) A comprehensive analysis of the effect of DSP4 on the locus coeruleus noradrenergic system in the rat. Neuroscience 166(1):279-291

Timmermans W, Xiong H, Hoogenraad CC, Krugers HJ (2013) Stress and excitatory synapses: from health to disease. Neuroscience 248:626-636. doi:10.1016/j.neuroscience.2013.05.043

Tsuruoka M, Tamaki J, Maeda M, Hayashi B, Inoue T (2011) The nucleus locus coeruleus/subcoeruleus contributes to antinociception during freezing behavior following the air-puff startle in rats. Brain Res 1393:52-61. doi:10.1016/j.brainres.2011.04.008

Valentino RJ, Van Bockstaele E (2008) Convergent regulation of locus coeruleus activity as an adaptive response to stress. Eur $\mathbf{J}$ Pharmacol 583(2-3):194-203

Valentino RJ, Foote SL, Aston-Jones G (1983) Corticotropin-releasing factor activates noradrenergic neurons of the locus coeruleus. Brain Res 270(2):363-367

Valls-Sole J (2012) Assessment of excitability in brainstem circuits mediating the blink reflex and the startle reaction. Clin Neurophysiol 123(1):13-20

Valls-Solé J (1998) Acustic and somatosensory prepulse modulation of the blink reflex and the startle reaction. In: Brainstem reflexes and functions. Litofinter, S.A, Madrid, pp 119-131

Vicentic A, Robeva A, Rogge G, Uberti M, Minneman KP (2002) Biochemistry and pharmacology of epitope-tagged alpha-1-adrenergic receptor subtypes. J Pharmacol Exp Ther 302(1):58-65

Wamsley JK, Alburges ME, Hunt MAE, Bylund DB (1992) Differential localization of alpha-2-adrenergic receptor subtypes in brain. Pharmacol Biochem Behav 41(2):267-273

Yeomans JS, Frankland PW (1995) The acoustic startle reflex: neurons and connections. Brain Res Brain Res Rev 21(3):301-314

Yeomans JS, Lee J, Yeomans MH, Steidl S, Li L (2006) Midbrain pathways for prepulse inhibition and startle activation in rat. Neuroscience 142(4):921-929 